\title{
ASUNTOS DE VECINOS: LANGOSTA, DEFENSA AGRÍCOLA Y LA CONSTRUCCIÓN DE LA SANIDAD VEGETAL EN MÉXICO Y CENTROAMÉRICA, SIGLO XX
}

\author{
Inés Ortiz Yam \\ Universidad Autónoma de Yucatán ${ }^{1}$ \\ María Cecilia Zuleta ${ }^{2}$ \\ El Colegio de México
}

\begin{abstract}
G 1 presente artículo propone un estudio histórico del combaEte de las plagas de langosta en México y Centroamérica en la primera mitad del siglo xx. El sur y el sureste mexicano comparten las mismas plagas agrícolas con los países de Centroamérica; la más importante por sus hábitos y su capacidad destructora de la cubierta vegetal es la langosta, Schistocerca piceifrons
\end{abstract}

Fecha de recepción: 4 de noviembre de 2019

Fecha de aceptación: 9 de enero de 2020

${ }^{1}$ Inés Ortiz Yam agradece el financiamiento recibido a través del proyecto "Reparto agrario: municipio, ejido y configuración político-territorial en el sur y en el oriente de Yucatán", de Ciencia Básica-Conacyt, clave 222620.

${ }^{2}$ María Cecilia Zuleta agradece el valioso apoyo que en distintas etapas del trabajo le brindaron Jesús Reyes Bautista (UNAM), Jorge Alberto Muñoz Enríquez (Universidad Veracruzana) y Donovan Najarro (Universidad Centroamericana José Simeón Cañas, San Salvador). Asimismo, agradece a Ximena López Carrillo (Stony Brook University, Nueva York) y a Maribel Rivas Vasconcelos (LAI Alumni Program, Freie Universität Berlin, Universidad 
(Walker). ${ }^{3}$ Se trata de un insecto que normalmente es solitario, pero que en tiempo de sequías o de inundaciones -vinculadas en ocasiones a fenómenos meteorológicos más amplios como las corrientes del Niño y la Niña-, ${ }^{4}$ se vuelve gregario, cambia su color, aumenta de tamaño y adquiere la capacidad para migrar hasta zonas distantes. Una manga de langosta es capaz de recorrer entre 30 y $60 \mathrm{~km}$ al día y desplazarse desde el nivel del mar hasta $2000 \mathrm{~m}$ sobre éste. ${ }^{5}$ Convertida en plaga, la langosta es capaz de devorar su peso al día, es decir, 1.5 gramos. Una manga de langosta de $20 \mathrm{~km}$ de ancho puede devastar y comer 300 toneladas de vegetación al día, ${ }^{6}$ destruyendo especialmente los cultivos de maíz y frijol, pasturas, algodonales, platanares, plantíos de frutales y hortalizas, y provocar la contaminación de las aguas. A su paso, la langosta detona catástrofes y emergencias sociales, alimentarias y económicas.

Las siguientes páginas escudriñan los métodos, instrumentos y medios con que fue combatido el acrídido a lo largo de la primera mitad del siglo xx en México. Por medio del estudio de las campañas que contra la langosta se desarrollaron en el país entre 1920 y la década de 1950, se reconstruye la formación de la defensa agrícola federal y del proceso de su institucionalización hasta el nacimiento de un sistema de sanidad vegetal y animal de alcance nacional y plenamente soberano, pero que converge con normas, regulaciones y organizaciones internacionales de

Autónoma Metropolitana-Xochimilco) por su generoso auxilio bibliográfico y de investigación. La Biblioteca Daniel Cosío Villegas de El Colegio de México proporcionó invaluable apoyo, en particular la asistencia experta del bibliógrafo doctor Víctor Julián Cid Carmona en la localización de fuentes. La responsabilidad por errores y omisiones es de la autora.

${ }^{3}$ Rodríguez Vallejo, Historia de la fitosanidad en México, p. 28.

4 Magaña Ortiz, "Estudio comparativo de la Langosta Centroamericana", pp. 24-24, 106-150.

5 García Quintanilla, “Saak’y el retorno del fin del mundo”, pp. 327, 331.

6 García Quintanilla, "Záatal: cuando los milperos perdieron el alma”, p. 145. 
control de plagas y sanidad fitopecuaria de alcance continental y global.

Es así como este artículo estudia la lucha contra la plaga de la langosta en dos momentos: el primero, nacional, en la década de 1920, que se enfoca principalmente en las campañas contra la langosta en Yucatán y Veracruz; y luego un segundo momento, mexicanocentroamericano, entre los años cuarenta y cincuenta, con la formación del Comité Internacional para el Combate contra la Langosta (CiCLA) en Centroamérica y México El análisis de la primera etapa, local y nacional, de las campañas contra la langosta reconstruye detenidamente cuándo, cómo y con qué instrumentos normativos y dispositivos científicos e institucionales se buscó combatir y controlar la plaga en el Golfo y la península de Yucatán, y explica el surgimiento de una política pública estatal y federal destinada a la defensa agrícola. El segundo momento, la campaña mexicano-centroamericana contra el acrídido entre las décadas de 1940-1950, se estudia de forma panorámica, como una experiencia que desbordó los principios y métodos de la defensa agrícola nacional, conduciendo a la creación de organismos de control y supervisión de la sanidad animal y vegetal a escala transnacional, a acuerdos intergubernamentales y a la creación de dispositivos e instrumentos de cooperación científica y técnica sanitaria para toda el área mesoamericana, impulsados por los gobiernos de la región y por una nueva organización producto del orden mundial posbélico, la Organización de las Naciones Unidas para la Alimentación y la Agricultura (FAO), fundada en octubre de 1945.

$\mathrm{Al}$ respecto, caben algunas precisiones. Toda plaga, cuando invade, altera el curso de la vida agrícola de los productores y la actividad económica general de las zonas infestadas, sobre todo los patrones de producción y consumo. ${ }^{7}$ Se ponen en juego

7 Un seguimiento puntual del impacto económico de una plaga en cada localidad infestada a lo largo de cuatro décadas, en Lange, Olmstead y Rhode, 
cambios en los valores y pautas de interacción social y material entre los actores de las poblaciones afectadas ante la escasez de alimento y el surgimiento de nuevas dinámicas sociales y demográficas, como la emigración. En México las plagas de langosta en la primera mitad del siglo xx afectaron principalmente los cultivos de maíz y frijol destinados al autoconsumo de la población rural y las pasturas que servían de alimento para los animales, lo que debió repercutir en la dinámica económica y social de las zonas agrícolas comerciales e industriales como el henequén, caña de azúcar, café, plátano, entre otros, del sureste y sur del país. Lo mismo en Centroamérica, hasta donde hemos podido comprobar para el periodo comprendido en este estudio. Empero, por su complejidad y amplitud, no nos detenemos aquí a estudiar las pérdidas agrícolas que causaron el desabasto y escasez de los productos básicos para el consumo interno, la posible importación de granos y demás impactos socioambientales de las invasiones de langostas. Tampoco se estudian aquí sus detonantes climáticos, meteorológicos y ambientales, por exceder el perímetro de nuestro estudio y sus posibilidades. ${ }^{8}$ En cambio, el artículo se concentra en el proceso histórico de formación de la defensa agrícola y sanidad vegetal

\footnotetext{
“The Impact of Boll Weevil”, una valoración sobre su impacto en la relocalización y reestructuración de la vitivinicultura europea, en PAN-MonTojo, "Las vitiviniculturas".

${ }^{8}$ Científicos han subrayado la vinculación entre el desarrollo de la plaga de langosta y fenómenos climáticos como El Niño, que rige las lluvias, sequías, tormentas e inundaciones. Contreras Servín, Conexión climática del fenómeno, señala esa coincidencia para los brotes en 1940-1941 y en 1953, p. 349. En Bajo el crepúsculo de los insectos, Luis Arrioja Díaz Viruell, relaciona las oscilaciones climáticas y los cambios ambientales al surgimiento y desarrollo de la plaga de la langosta en el Reino de Guatemala del siglo xviII. Demuestra que las condiciones climáticas y ambientales propiciaron mutaciones, cambios en la conducta y en las formas en que se alimentaba el insecto, circunstancias que dejaron en total vulnerabilidad a las estructuras agrarias.
} 
como una cuestión de política, gobierno, ciencia y tecnología. ${ }^{9}$ Desde ese ángulo nos referimos a dos momentos de las plagas de langosta en la primera mitad del siglo xx, con la mirada puesta en las innovaciones institucionales que desencadenaron nuevos tipos de organizaciones para el control y defensa ante brotes de enfermedades y plagas agrícolas, que conforme se afianzaban y especializaban sus funciones, fueron conjugando la interacción de burócratas, tecnoburócratas, y científicos. ${ }^{10}$

El estudio de las plagas, sus efectos devastadores en la agricultura y la forma en que las sociedades agrícolas se han enfrentado a ellas tienen una larga tradición en la historiografía social, agraria, económica, ecoambiental y de los desastres naturales, ${ }^{11}$ y más recientemente, en estudios de historia agraria y de la ciencia que convergen con la historia de la globalización. ${ }^{12}$ En México, una abundante literatura ha vinculado a las plagas de langosta con las crisis agrícolas y demográficas, predominando las

${ }^{9}$ Un análisis profundo de las estrategias de los campesinos, empresarios, hacendados, rancheros y compañías agrícolas para enfrentar la plaga de langosta queda por ahora al margen de este artículo, por merecer otro estudio específico.

10 En esa línea, una obra inspiradora, Olmstead y Rhode, Arresting Contagion, pp. 1-19, 316-322; también, Deveson y Martínez, "Locusts in Southern Settler Societies".

${ }^{11}$ Por ejemplo, sin mencionar los muchos estudios sobre la plaga de la filoxera en Europa, las plagas y enfermedades del algodón, los cítricos y el ganado en Estados Unidos y Sudamérica, así como otras plagas en México, véanse: МсСоок, "Plantas, petróleo", y el estudio de Soluri, "People, Plants and Pathogens", que abrió brecha. Otro enfoque, socioagrario y de políticas públicas para el caso de la langosta en Argentina, el país donde más daños causaron estos insectos a lo largo de la primera mitad del siglo xx, en TranchinI, "Políticas".

12 Dos potentes análisis sobre plagas y patógenos, ciencia global y local, agricultura y globalización, en McCoOK, "Las epidemias liberales”, y FERnÁNDEZ Prieto, "Islands of Knowledge", pp. 792-794. Recientemente, un sugerente estudio en PORTER, "Plagas, pesticidas". 
investigaciones regionales, y para el periodo colonial. ${ }^{13}$ En años recientes, la preocupación por las plagas y enfermedades de plantas y animales, y por la plaga de langosta en particular, ha estado presente en estudios de ciencia y biología, de las políticas públicas, de historia de la naturaleza y el medioambiente. ${ }^{14}$ Las plagas de langosta también han sido objeto de investigaciones socioantropológicas y etnohistóricas que profundizan en la cultura y la reconstrucción simbólica del insecto, sobre el que se han tejido significados y saberes. ${ }^{15}$ Este trabajo dialoga con las investigaciones precedentes, pero enfoca su atención en el siglo xx. Sobre la base de fuentes inéditas de archivos locales, diplomáticos, publicaciones oficiales y hemerografía mexicana y centroamericana, se sugiere que, en el control de la plaga de la langosta, se contribuyó al conocimiento entomológico del insecto y a la edificación de la defensa agrícola mexicana en la primera mitad del siglo xx.

\section{LUCHAS LOCALES:}

EL COMBATE A LA PLAGA DE LANGOSTA

EN YUCATÁN Y VERACRUZ

En 1923 enjambres de langosta comenzaron a ser vistos en varias partes del sur y sureste mexicano. Su procedencia se desconoce.

13 Véase García Quintanilla, "La langosta, los mayas y el colonialismo”; Peniche Moreno, Tiempos aciagos, pp. 167-214; y Arrioja Díaz Viruell, "Enjambres y nubarrones” y "Guatemala y Nueva España”. Este autor editó y coordinó un dossier de investigaciones específicas sobre la langosta en la revista Relaciones, 129 (2012).

14 Entre las plagas y enfermedades que afectaban la agricultura y las agroindustrias, y el comercio de exportación, están: la fiebre aftosa, la garrapata y la tuberculosis del ganado, el picudo y el gusano rosado del algodón, el chahuixtle del trigo, la mosca de los cítricos, la roya y otras enfermedades del cafeto, el chamusco del plátano, y las enfermedades de la papa y de la piña, entre otras. 15 Alberola Romá, Riesgo, desastre y miedo; Few, "Killing Locust”; León Vegas, "La plaga con que castiga Dios”; Magaña Ortiz, "Estudio comparativo”; Mas Galváñ, "La gestión de la catástrofe”; Peraldo Huertas, "Plagas de langosta”. 
Pero el doctor Carlos Cristian Hoffmann, jefe de la Comisión Científica Exploradora de la Plaga de la Langosta en el Estado de Veracruz, consideró que las primeras mangas voladoras llegaron del Petén de Guatemala. ${ }^{16}$ Se fueron hacia el norte hasta llegar a Campeche y Yucatán, y posteriormente se desplazaron a Tabasco, Chiapas y Veracruz. La pradera interior de la tierra caliente de Veracruz era un medio favorable para el desarrollo de la langosta. Para 1924, era "el centro de toda la plaga", ${ }^{17}$ la cual se había extendido a Veracruz, Puebla, San Luis Potosí, Oaxaca, Tabasco, Yucatán y Campeche.

Esta plaga de langosta no era la primera que padecía el territorio mexicano, pero sí la primera que enfrentaba el gobierno que recién emanaba de la Revolución. Durante el siglo xix la irrupción de plagas había provocado esfuerzos privados e intentos gubernamentales de organización de una defensa agrícola y pecuaria. ${ }^{18}$ Antes de la primera guerra mundial, las provisiones

16 Carlos C. Hoffmann (1876-1942) llegó de Frankfurt, Alemania, en 1901. Para 1923 era jefe de Parasitología del Instituto de Higiene. Fue uno de los fundadores del Instituto de Biología de la UNAM (1929). En 1927 colaboró con el Instituto de Enfermedades Tropicales de Hamburgo. Es considerado el fundador de la parasitología médica mexicana, con investigaciones sobre artrópodos y parásitos causantes de enfermedades humanas (malaria, oncocercosis, y especialmente la enfermedad llamada úlcera de los chicleros de Yucatán y Belice, leishmaniasis americana). Sobre los chicleros véase el texto de David Pretel en este mismo dossier. Hoffmann fue representante de la Comisión de Malaria de la Sociedad de Naciones y trabajó con la Fundación Rockefeller en diversos proyectos desde 1935. Véase Martínez Marañón, “Carlos Cristian Hoffmann".

17 Informe de la Comisión Científica, p. 20; Diario Oficial de Yucatán (7 dic. 1925).

18 Véase Arrioja Díaz Viruell, “Enjambres y nubarrones”; Romero ConTRERAs, "Los agrónomos mexicanos". También "La defensa contra los enemigos de la agricultura”, El progreso de México (15 oct. 1898), p. 45-46; “Acción contra las plagas, ¿del Estado o particulares?”, El Progreso de México (15 sep. 1897), pp. 185-186. El profesor de la Escuela Nacional de Agricultura, José C. Segura, había sido comisionado a fines de la década de 1880 para estudiar en el territorio la plaga de langosta; véase nota 62. 
científicas para eliminar la plaga de la langosta fueron materia de intercambio consular entre México y Sudamérica. ${ }^{19}$ Incluso, en plena guerra revolucionaria, 1916, la defensa contra un brote de infestación de los plantíos de algodón en la Comarca Lagunera fue conducida por la Cámara Agrícola Local y los empresarios algodoneros, sin recibir suficiente atención del presidente Venustiano Carranza ni de la Comisión de Plagas del Departamento de Parasitología Agrícola de la Secretaría de Fomento. ${ }^{20}$

El 22 de septiembre de 1923 el presidente municipal de Tlacotalpan, Veracruz, en la ribera del Papaloapan, envió un telegrama al presidente de República, Álvaro Obregón, informando que su municipio se encontraba "plagado considerablemente de langosta" debido al deficiente trabajo de la Secretaría de Agricultura. La respuesta del presidente a la irrupción de la langosta en el Golfo revela que todavía en 1923 el gobierno mexicano no tenía previsiones ni claridad sobre el papel que debía desempeñar frente a una urgencia fitosanitaria. Respondió que eran "los vecinos azotados [...] los más obligados a combatirlas y desgraciadamente han demostrado una gran apatía para defender sus propios intereses". De esta forma, el ejecutivo federal dejaba la responsabilidad de lidiar con la emergencia causada por esta plaga a los campesinos, agricultores y vecinos cuyos cultivos eran afectados por el acrídido. ${ }^{21}$ Pocos días después, el 27 de septiembre de 1923, el gobernador de Veracruz solicitó al presidente de la República ayuda para "nuestra dificilísima situación" por causa de la langosta, que amenazaba invadir otros estados. Se le informó que el presidente había enviado "amplias instrucciones" a la Secretaría de Agricultura para combatir la plaga, pese a "lo exhausto de nuestro erario y [los] pocos elementos

\footnotetext{
19 La destrucción de la langosta, Informe rendido.

20 Ohlendorf, Studies of the Pink.

21 AGN, $P$, O-C, c. 169, exp. 426 P-2. Álvaro Obregón a Edmundo Rojas (presidente municipal de Tlacotalpan) (24 de septiembre de 1923).
} 
de citado ministerio". ${ }^{22}$ En esos años posrevolucionarios, el gobierno federal apenas se estaba afianzando, no contaba con recursos y tenía otras prioridades más urgentes, como el abasto de alimentos, las reclamaciones extranjeras y la pacificación del país. Eran visibles las limitaciones burocráticas, científicas, técnicas, materiales y financieras de la Secretaría de Agricultura y Fomento, por lo que en un comienzo no hubo una estrategia definida para combatir al acrídido desde la federación.

En Yucatán, las primeras mangas de langosta se presentaron en 1923, durante el gobierno del agrarista Felipe Carrillo Puerto. Por entonces, el cultivo de henequén para la exportación de su fibra constituía la actividad económica más importante..$^{23} \mathrm{La}$ Liga de Resistencia, creada en 1917 para respaldar al Partido Socialista de Yucatán, y que representaba tanto a trabajadores rurales como urbanos organizados en ligas locales, propuso a la legislatura estatal una ley para organizar los esfuerzos de exterminio de la langosta. ${ }^{24}$ En noviembre de ese año envió a la Legislatura una iniciativa que declaraba de "utilidad pública y de urgente necesidad la destrucción de la langosta en todo el estado" y depositaba en las autoridades municipales la responsabilidad de organizar las brigadas encargadas de matar al acrídido. ${ }^{25}$ El 25 de julio de 1924 la legislatura yucateca

\footnotetext{
22 AGN, $P$, O-C, c. 169, exp. 426 P-2. Edmundo Rojas (presidente municipal de Tlacotalpan) a Álvaro Obregón (27 de septiembre de 1923), Álvaro Obregón a Edmundo Rojas (presidente municipal de Tlacotalpan) (28 de septiembre de 1923).

${ }^{23}$ Un año antes, en 1922, el henequén yucateco todavía tenía una participación de $75 \%$ de la oferta mundial de esa fibra. Canto Sáenz, Del henequén, p. 59. ${ }^{24}$ De acuerdo con las cifras oficiales, en 1922 había en Yucatán 417 ligas con un total de 73000 agremiados. Paoli y Montalvo, El socialismo olvidado, p. 55; SAVArino, Pueblos y nacionalismo, pp. 378-380; JosePh, "El caciquismo y la Revolución”, p. 270.

25 AGEY, Congreso del Estado, Comisión de Gobernación, c. 63, vol. 13, exp. 11. De acuerdo con esta iniciativa, todos los hombres y mujeres de entre $14 \mathrm{y}$ 50 quedaban obligados a entregar "su contingente personal".
} 
declaraba de "utilidad pública y de urgente necesidad la destrucción de la langosta”. La nueva disposición territorializó el combate a la langosta al determinar que la autoridad municipal era responsable de los trabajos de destrucción de la langosta ejecutados por el contingente personal de los adultos menores de 60 años. Cada municipio recaudaba mensualmente, en "cajas de auxilio" y esos fondos se transferían al ejecutivo estatal para su empleo conforme a las necesidades de la campaña. ${ }^{26}$ Destaca en la ley una primera innovación en el concepto de campaña: se considera de "utilidad pública" la destrucción del acrídido. Es decir, el acto de destruir a la langosta se convirtió en un asunto de interés y conveniencia pública.

La ley yucateca de 1924 contra la langosta impuso reglas para combatirla, obligaciones a las autoridades y a la población, y penalidades y sanciones pecuniarias por incumplimiento, incluso la destitución de autoridades. ${ }^{27}$ Instrumentó dos antiguas estrategias: el financiamiento económico local ${ }^{28}$ y la organización colectiva de la población mediante brigadas para matar y capturar a la langosta, un nuevo nombre para una tarea practicada tradicionalmente por los milperos en Yucatán. ${ }^{29}$ Por su parte, las ligas de resistencia participaron activamente en la matanza del acrídido. Unas veces de manera independiente; es decir, convocando a sus miembros para acordar y organizar

\footnotetext{
26 AGEY, Congreso del Estado, Comisión de gobernación, c. 63, exp. 11.

27 Diario Oficial de Yucatán (2 ago. 1924).

28 AGEY, Congreso del Estado, Comisión de gobernación, c. 63, exp. 11.

${ }^{29}$ Los milperos solían adentrarse en los montes en busca de los huevecillos de langosta, sitos en los recovecos de arbustos y henequenales. Los huevecillos, las ninfas y las voladoras capturados eran colocados en bolsas e incinerados inmediatamente. García Quintanilla, "Záatal: cuando los milperos perdieron el alma”, p. 149. En Oaxaca los pueblos solían enfrentar las plagas de langosta con cuadrillas exterminadoras, Arrioja Díaz Virueld, "Enjambres y nubarrones", p. 182.
} 
las salidas para matar al acrídido, ${ }^{30}$ y otras bajo las órdenes de la autoridad municipal. ${ }^{31}$

Mientras tanto, el Departamento de Fomento y Agricultura de Veracruz comenzó a seguir el asunto, formando la Junta de Defensa contra la Langosta para dirigir las tareas de exterminio en Córdoba, ${ }^{32}$ centro de los negocios cafetaleros de exportación, presidida por una Junta Central en la capital del estado y por juntas regionales de defensa en las cabeceras de los excantones. Esta junta debía dirigir todos los trabajos de las juntas de defensa y juntas auxiliares y de vigilancia en los municipios, pueblos y localidades. ${ }^{33}$ Destaca la integración de personal especializado en esta junta: al lado de varios burócratas, cuatro parasitólogos se encargaban de investigar sobre los hábitos, biología y patrones de comportamiento del acrídido, cuatro ingenieros debían cuidar y vigilar las principales líneas férreas, y siete visitadores se ocupaban de distribuir combustible y víveres entre los damnificados. ${ }^{34}$ Para septiembre de 1924, en 10 de los 18 excantones se habían formado juntas regionales, a saber: Jalapa, Jalacingo, Coatepec, Córdoba, Orizaba, Veracruz, Los Tuxtlas, Cosamaloapan, Acayucan y Minatitlán. ${ }^{35}$

\footnotetext{
30 AGEY, Poder Ejecutivo, Gobernación 2, c. 796, leg. 2.

31 AGEY, Poder Ejecutivo, Gobernación 2, c. 797, leg. 1. En julio de 1924 el presidente municipal de Temax dispuso la salida diaria de 30 a 50 hombres para matar langosta. Esta disposición la extendió a las demás autoridades municipales y presidentes de ligas de la jurisdicción municipal para que organizaran a su población. AGEY, Poder Ejecutivo, Gobernación, c. 797.

32 AGN, $P, O-C$, c. 169, exp. 426 P-2. El presidente municipal de Córdoba, Veracruz, a Álvaro Obregón (presidente de México) (9 de mayo de 1924).

33 AGN, $P, O-C$, c. 169, exp. 426 P-2. Encargado de la sección cuarta del Departamento de Agricultura y Fomento a Álvaro Obregón (presidente de México) (19 de septiembre de 1924).

34 AGN, P, O-C, c. 169, exp. 426 P-2. Carta del Estado de Veracruz e informe que demuestra los trabajos emprendidos para combatir la plaga de langosta (19 de septiembre de 1924).

35 AGN, $P, O-C$, c. 169, exp. 426 P-2. Informe de los trabajos emprendidos para combatir la plaga de langosta en el estado de Veracruz (23 de septiembre de 1924).
} 
Entre agosto y septiembre de 1924 el gobernador de Veracruz, Adalberto Tejeda -quien sobresalía entre los gobernadores por su política agrarista radical de reparto de tierras, movilización de los campesinos en ligas agrarias y fomento a la educación agrícola socialista- tomó cartas en el asunto gestionando el uso gratuito de los principales medios de transporte para las tareas de exterminio de la langosta. El ferrocarril sería utilizado para el traslado de petróleo, gasolina y chapopote, que algunas compañías petroleras habían donado a las localidades afectadas. ${ }^{36}$ Fijó gastos extraordinarios para atender la campaña contra la langosta. También solicitó franquicias de los servicios federales: libre pasaje para que todos los empleados comisionados de la Junta Central se desplazaran por ferrocarril a los lugares invadidos sin costo alguno; ${ }^{37}$ libre porte para los telegramas y libre pase de la correspondencia, bultos postales y mercancías destinadas a la campaña contra la langosta. ${ }^{38}$ Pese a todo, las autoridades veracruzanas reconocieron que los resultados de la lucha contra la langosta no eran los esperados; los conflictos agrarios también dificultaban el combate. La Junta Regional de Córdoba explicó que todo el excantón estaba fuertemente invadido por mangas de langosta voladora proveniente de Huatusco, y que la

\footnotetext{
36 AGN, P, O-C, c. 169, exp. 426 P-2. Adalberto Tejeda (gobernador de Veracruz) a Álvaro Obregón, 4 de agosto de 1924, y respuesta recibida (5 de agosto de 1924).

37 AGN, P, O-C, c. 169, exp. 426 P-2. Ramón P. de Negri (secretario de Agricultura y Fomento) a Álvaro Obregón, (30 de agosto de 1924).

38 AGN, $P, O-C$, c. 169, exp. 426 P-2. Álvaro Obregón a Gonzalo Vázquez Vela (gobernador interino de Veracruz) (5 y 6 de septiembre de 1924); Álvaro Obregón a Amado Aguirre (secretario de comunicaciones) (6 de septiembre de 1924); Álvaro Obregón a Gonzalo Vázquez Vela (circa 6 de septiembre de 1924); Adalberto Tejeda a Álvaro Obregón (9 de septiembre de 1924). Sobre las demás entidades que también sufrían la invasión de la plaga todavía sabemos poco; véase Ángel Castillo Lanz (gobernador de Campeche) a Álvaro Obregón (27 de septiembre de 1924).
} 
presencia de "rebeldes que continuamente visitan los poblados" imposibilita todo trabajo tendiente a su exterminio. ${ }^{39}$

A principios del segundo semestre de 1924 la plaga de langosta se extendía a más de la mitad del territorio veracruzano, por lo que las autoridades veracruzanas demandaron la urgente intervención del gobierno federal. En agosto de 1924, el gobernador Tejeda entrevistó a Álvaro Obregón, consultando "en qué forma puede cooperar [el] gobierno federal” en la erradicación de la plaga de langosta. ${ }^{40}$ Poco después, el ejecutivo veracruzano pidió "pulverizadores, lanzallamas y substancias insecticidas" y la intervención de la Secretaría de Guerra y Marina para el posible uso de aeroplanos como "arma para combatir la plaga", al tiempo que informaba de la presencia de 14 agrónomos, 14 parasitólogos y personal técnico del Departamento de Salubridad. Finalmente, solicitó que el $\mathrm{H}$. Congreso de la Unión estudiara la posibilidad de una "ley de plaga”, así como el diseño de un plan económico para "la mayor ayuda pecuniaria posible". ${ }^{41}$

A la luz de esta información, es evidente que desde Veracruz se transformaba el concepto mismo de campaña de defensa agrícola: ya no se trataba como un asunto de política y organización burocrática y fiscal, o asunto municipal, sino que se concebía como una operación que implicaba varios niveles de gobierno, compleja, y que exigía un plan comprensivo para el control de las plagas. Todo plan requeriría de fundamentos científicos, de la investigación en campo de científicos y técnicos

39 Se refiere probablemente al movimiento agrarista local, conformado por organizaciones armadas de obreros y campesinos: precisamente en marzo de 1923 se había formado la Liga de Comunidades Agrarias del estado de Veracruz, AGN, $P$, O-C, c. 169, exp. 426 P-2. Informe de los trabajos emprendidos para combatir a la plaga de langosta en el estado de Veracruz (23 de septiembre de 1924).

40 AGN, P, O-C, c. 169, exp. 426 P-2. Álvaro Obregón a Eduardo de Gortari (presidente de la Junta Central) (8 de septiembre de 1924).

41 AGN, P, O-C, c. 169, exp. 426 P-2. Gonzalo Vázquez Vela (secretario de gobierno de Veracruz) a Álvaro Obregón (8 de septiembre de 1924). 
especializados, del empleo de dispositivos e instrumentos mecánicos y, sobre todo, de la creación de instituciones, junto con un marco legal y un presupuesto económico para sufragar cualquier campaña, así como un plan de auxilio a los afectados. Fue también en Veracruz donde voces expertas comenzaron a señalar que el problema de la plaga debía ser considerado un problema nacional, de competencia de la federación y los estados de toda la República, aun cuando no sufrieran los estragos de la invasión de langosta: la Junta Regional de Defensa contra la plaga de langosta, con sede en Córdoba, en sesión extraordinaria, sugirió "respetuosamente" al presidente de la República comunicar a la "nación entera [la] necesidad de cooperar en la campaña contra el voraz insecto, que asola en cinco estados de la República y que amenaza con invadir a todo el país". De no contar con la cooperación nacional -afirmaba- el país corría el riesgo de caer en la "ruina más espantosa y como consecuencia en el hambre y la peste". ${ }^{42}$ En 1924 la Secretaría de Agricultura y Fomento y el gobierno del estado de Veracruz convocaron a los representantes de las cámaras de comercio de Veracruz, Orizaba, Córdoba, Puerto México, Pueblo Viejo, Industrial de Orizaba y a la Sociedad Agrícola Coatepecana para solicitarles su colaboración a fin de sufragar la campaña contra la langosta. Los representantes de las cámaras argumentaron no poder otorgar recurso alguno y propusieron un impuesto extraordinario de $2 \%$ adicional sobre las importaciones por seis meses para combatir esta "calamidad que más que regional de Veracruz puede considerarse nacional". ${ }^{43}$

${ }^{42}$ AGN, $P$, O-C, c. 169, exp. 426 P-2. F. J. Kell (presidente de la Junta Regional de Defensa contra la plaga, de Córdoba) a Álvaro Obregón (5 de septiembre de 1924), y respuesta recibida (6 de septiembre de 1924).

${ }^{43}$ No obstante, ese nuevo impuesto no fue autorizado. AGN, $P, O-C$, c. 169, exp. 426 P-2. Ramón Carrillo, E. G. Muñoz, W. K. Boon y Vicente Mora a Álvaro Obregón, 16 de octubre de 1924; respuesta de Álvaro Obregón a Ramón Carrillo y demás firmantes (17 de octubre de 1924). 
Los gobiernos de Yucatán y Veracruz respondieron de forma institucional al problema de la invasión de langosta en sus estados. Cada entidad tuvo que responsabilizarse de los métodos y las formas para acabar con el acrídido; la cooperación interestatal se mostraba casi imposible. Por ejemplo, en agosto de 1924, el gobernador de Veracruz solicitó al de Yucatán apoyo económico para sostener la campaña contra la plaga, pero éste respondió no poder colaborar por también sufrir "el azote de la funesta plaga" y tener que "atender con urgencia a los gastos que reclaman constantemente las necesidades de la campaña de extinción del insecto". ${ }^{44}$ Pese a la escasa coordinación y colaboración entre los gobiernos estatales, la importancia de sus acciones radica en la respuesta institucional que le dieron al problema de la langosta. Fueron los gobiernos estatales las primeras autoridades en asumir la tarea de fijar un plan para el exterminio de la langosta y advertir sobre la necesidad de que interviniera el gobierno federal. En el proceso, se crearon instituciones y reglamentos, se establecieron procedimientos de combate, se planeó el financiamiento y se impulsaron técnicas para erradicar al acrídido. Fue tal su importancia que algunas de las acciones y estrategias legales, económicas y operativas diseñadas por los gobiernos locales fueron recuperadas y retomadas por las autoridades federales poco después.

\section{LA PRIMERA CAMPAÑA NACIONAL, 1924-1926}

En nuestro país la campaña contra la langosta nunca se ha llevado a efecto de un modo metódico y ordenado antes de este año. Antiguamente fueron las autoridades aisladas de las regiones devastadas o los particulares, quienes usaron los métodos empíricos que pensaban les darían mejor resultado. Hasta que el gobierno actual que

${ }^{44}$ AGEY, Poder Ejecutivo, Gobernación 2, c. 776, leg. 1 (1922-1923). 
reglamentó convenientemente la campaña, nada se había ensayado y nada se había hecho dentro de un plan técnico y apropiado. ${ }^{45}$

En agosto de 1924 Ramón P. de Negri, secretario de Agricultura y Fomento, se trasladó al estado de Veracruz y pudo constatar que en la lucha contra la langosta participaban "los gobiernos estatales afectados, las comunidades campesinas y grupos comunistas, sindicatos obreros y de agricultores en pequeño", quienes han formado comités que trabajan bajo las instrucciones de técnicos y del gobierno local. ${ }^{46}$ También observó la existencia de una infraestructura creada para erradicar la langosta, como eran las juntas de defensa, y registró la situación de los excantones afectados por la plaga. Durante su visita, De Negri se percató de la renuencia de los hacendados a colaborar en la lucha contra la langosta, por lo que sugirió emitir un decreto para obtener "la cooperación disciplinada de apáticos que se limitan a criticar cualquier esfuerzo sin participación alguna". ${ }^{47}$

El 31 de octubre de 1924 Álvaro Obregón, después de leer ese informe, dispuso que la Secretaría de Agricultura y Fomento se abocara a la lucha antiacrídido. ${ }^{48}$ Pero un mes antes, en septiembre de 1924, ya se habían dado pasos importantes para la intervención del gobierno federal en dos planos: el sustento legal a la acción misma de combatir la plaga, y la creación de un fondo económico para esos fines. El departamento jurídico elaboró un acuerdo presidencial que declaraba la campaña contra la

${ }^{45}$ La plaga de langosta en México, pp. 101-102.

${ }^{46}$ La participación de las organizaciones campesinas comunistas y ligas agrarias contra la plaga de langosta y otras plagas, como las de los cítricos en Veracruz, es aún poco conocida.

47 AGN, P, O-C, c. 169, exp. 426 P-2. Ramón P. de Negri (secretario de Agricultura y Fomento) a Álvaro Obregón (8 de septiembre de 1924).

48 AGN, $P, O-C$, c. 169, exp. 426 P-2. Álvaro Obregón a Eduardo de Gortari (presidente de la Junta Central de la campaña contra la langosta, Jalapa, Veracruz) (31 de octubre de 1924). 
langosta de "utilidad pública" para la nación. ${ }^{49}$ Esta declaración le permitía al gobierno federal adoptar las medidas que fueran necesarias para hacer frente a situaciones de emergencia por causa del acrídido, que le afectaban como entidad política. ${ }^{50}$ Así, el 13 de octubre de 1924 se amplió la partida prevista de 8559 a 100000 pesos, destinada a sufragar la campaña contra la langosta, disponiendo el presidente que este decreto se promulgara inmediatamente por ser un "caso de suma urgencia". ${ }^{51}$

La intervención del gobierno federal se volvió más contundente al aprobarse, el 29 de noviembre de 1924, la Ley de Plagas de los Estados Unidos Mexicanos conocida como Ley Federal de Plagas. ${ }^{52}$ Con un total de seis capítulos, esta establece el concepto de plaga agrícola y pecuaria, y otorga la capacidad jurídica al Estado mexicano para diseñar, decidir y dirigir las labores de su destrucción; definiendo como plaga agrícola a "todo agente animal o vegetal que ataque las plantas cultivo; los animales o vegetales cuya explotación esté relacionada con la agricultura y los productos de ambos, causando en todo o en parte su destrucción, desmejorando o rebajando anormalmente su rendimiento ordinario, con grave perjuicio económico". ${ }^{53}$

De esta forma, se retomaban los principios de la Ley de Servicios Agrícolas Federales dictada en 1909 bajo el influjo del entonces secretario de Fomento, Olegario Molina, quien había

49 AGN, P, O-C, c. 169, exp. 426 P-2; telegramas del secretario de Agricultura al presidente de la República (27 de septiembre de 1925), en AGN, P, O-C, c. 169, exp. 426 P-2; telegramas del presidente de la República al secretario de Agricultura (29 de septiembre de 1925), en AGN, P, O-C, c. 169 , exp. 426 p. 2.

${ }^{50} \mathrm{La}$ utilidad pública es la conveniencia o el interés de la masa de los individuos del estado; se antepone a la utilidad particular. Escriche, Diccionario razonado, p. 706.

51 AGN, P, O-C, c. 169, exp. 426 P-2. Álvaro Obregón a A. J. Pani (secretario de Hacienda) (13 de octubre de 1924).

52 "Ley de Plagas", en La plaga de langosta en México, p. 152.

53 “Ley de Plagas", en La plaga de langosta en México, p. 153. 
establecido la competencia exclusiva de la Secretaría de Fomento, Colonización e Industria en la dirección del combate a las plagas: dirigir, orientar, nombrar comisiones nacionales y regionales, y auxiliar a las autoridades en todos los niveles del gobierno en las tareas de exterminio. Más importante aún, retomando los debates internacionales sobre los mecanismos cuarentenarios como método de control de plagas, así como las disposiciones de los socios comerciales con quienes se daba el comercio de bienes agropecuarios, esta ley de 1924 fijó la plena competencia de la Secretaría de Agricultura y Fomento para establecer cuarentenas interiores y exteriores, y proveer los medios materiales para el combate, prevención y extinción de las plagas y enfermedades, en colaboración con la Secretaría de Hacienda y Crédito Público y el Departamento de Salubridad Pública. ${ }^{54}$

Poco después, en febrero de 1925, el presidente Plutarco Elías Calles expidió el Reglamento de la ley federal de plagas en lo relativo a la campaña contra la langosta, que recupera muchas de las disposiciones legales, operativas e institucionales puestas en marcha en las entidades afectadas, como Yucatán y Veracruz. Por ejemplo, en el ámbito jurídico, la campaña para combatir y extinguir la langosta es declarada de "utilidad pública"; Yucatán fue el primer estado en considerar las acciones de exterminio de la langosta bajo dicho concepto jurídico. Asimismo, otro aspecto recuperado de las experiencias estatales en la ley federal fue la arquitectura institucional: las juntas de auxilio y defensa, tanto en las localidades como en las capitales, una estructura jerarquizada.

Este fue el caso de la Junta Nacional Directora de la Campaña contra la Langosta, organismo autónomo con sede en el estado de Veracruz, fundado para planear, organizar y dirigir el combate para la erradicación de la langosta en todo el país, recuperando así la experiencia organizativa previa en ese estado

${ }^{54}$ La presencia de la sanidad vegetal, p. 16. 
para enfrentar al acrídido. ${ }^{55}$ Esta Junta Nacional integraba, de forma jerarquizada y vertical, el mosaico de poderes estatales y federal para el combate a la langosta: un presidente -el director general de Agricultura y Ganadería- un secretario técnico agrónomo - designado por la Secretaría de Agricultura y Fomento-y un vocal por cada uno de los estados que padecían la presencia de la langosta. De ella dependerían las jefaturas de zona y las juntas centrales, regionales y locales. Mientras, en cada uno de los estados invadidos por langosta -en este caso San Luis Potosí, Puebla, Oaxaca, Chiapas, Tabasco, Campeche y Yucatán, tal como muestra el mapa 1-, debía formarse una junta central con cinco miembros designados por el gobernador. En todas estas instancias se debían obtener los fondos económicos y los elementos para la campaña, alentar la participación de la población en la lucha contra la langosta, e informar a las autoridades políticas de los avances en la erradicación de la misma. ${ }^{56}$

La formación y uso de las brigadas de destrucción como método principal de combate a la langosta fue también recuperado de la experiencia en Yucatán y Veracruz, y sería una estrategia recurrente todavía dos décadas después, como se verá. El Reglamento de 1925 fijó normas de participación en el combate a la langosta: todos los habitantes entre 15 y 50 años de las zonas invadidas quedaron obligados a participar en las campañas, con excepción de las mujeres y los incapacitados. En el nuevo marco normativo, los propietarios, arrendatarios u ocupantes de terrenos y las empresas ferroviarias también quedaban obligados a contribuir en el combate contra la langosta. La participación de los hacendados, empresas y demás particulares, como pudo constatar el secretario de Gobierno, Ramón P. de Negri durante su visita al estado de Veracruz en agosto de 1924, era limitada

55 "Reglamento de la ley federal de plagas", en La plaga de langosta, pp. 159160; Navarro de Palencia, Los servicios fitopatológicos, p. 16.

56 "Reglamento de la ley federal de plagas", en La plaga de langosta, pp. 160-161. 


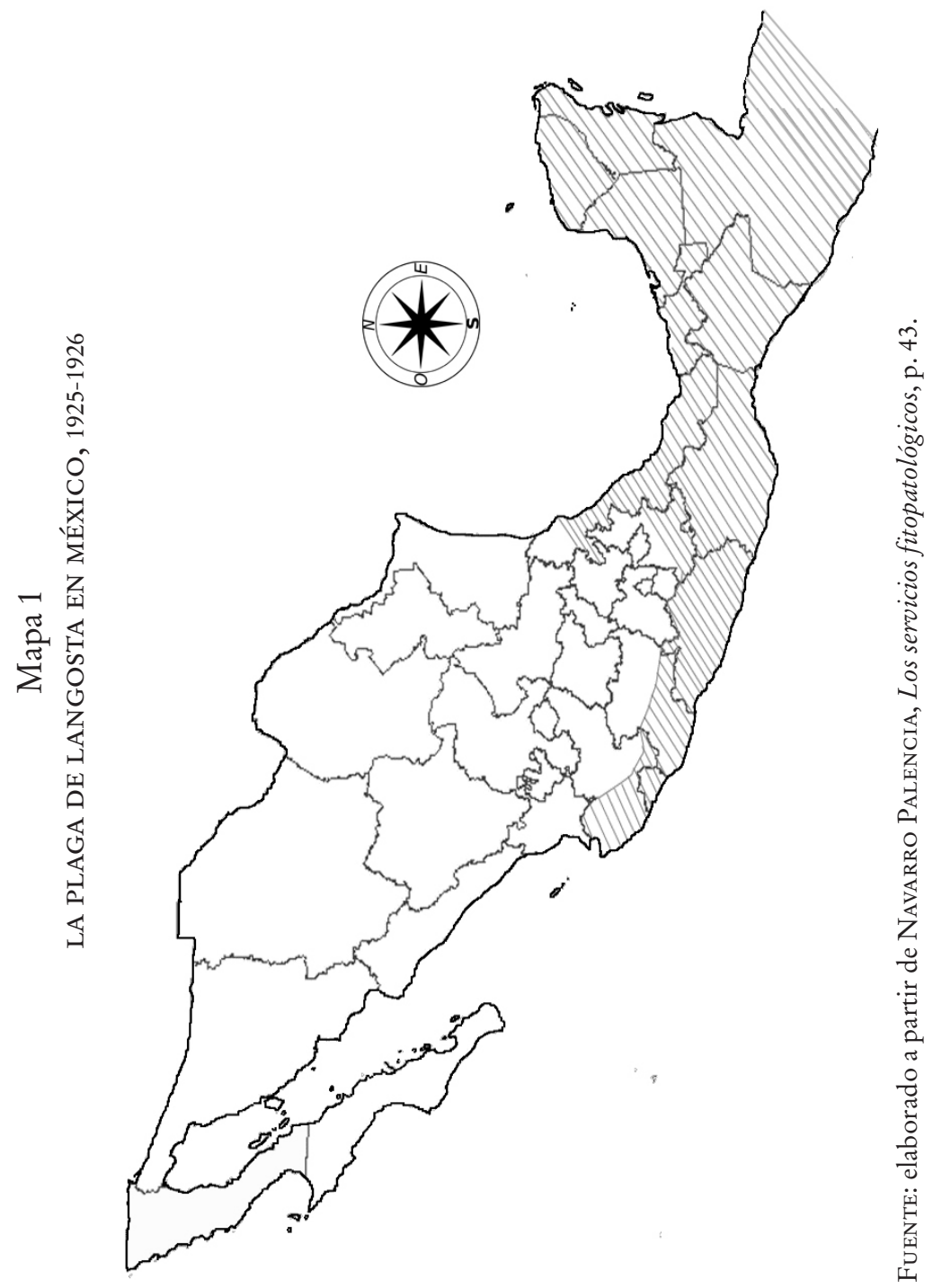


y con muchas reticencias. ${ }^{57}$ Quienes no participaran en la destrucción del acrídido, serían multados. ${ }^{58}$ En suma, la Ley Federal de Plagas de 1924 y su Reglamento de 1925 marcaron el inicio de una organización institucional específica y una política pública destinada a la defensa agrícola. En este sentido, las invasiones del acrídido dejaron de ser consideradas un problema de particulares, campesinos o gobiernos locales y estatales, para convertirse en un asunto de la nación, en el que el gobierno federal por medio de sus organismos competentes y por intermedio de su aparato administrativo y agencias especiales, como la Junta Nacional Directora de la Campaña, quedaba como responsable de prevenir, diseñar e instrumentar el combate a las plagas y enfermedades de plantas y animales. ${ }^{59}$

Esta pauta de centralización no era el único camino posible para edificar la defensa agrícola y el control de plagas, tan sólo en América del Norte se pueden encontrar distintas formas y principios de organización de la defensa agrícola y salud animal. Entre fines del siglo xIx y las dos primeras décadas del Xx en Estados Unidos y Canadá, parte de los dominios británicos, se fue institucionalizando el control de plagas. ${ }^{60}$ Antes de la primera guerra mundial, ambas naciones lograron definir y uniformar su legislación e instrumentos fitosanitarios ("Plant Quarantine Act”, 1912, de Estados Unidos, “Destructive Insects and Pests Act”, Canadá, 1910), así como varios países

\footnotetext{
57 "Reglamento de la ley federal de plagas", en La plaga de langosta en México, pp. 162-164.

${ }^{58}$ La ley local del estado de Yucatán ya había previsto la obligatoriedad de la participación de los hacendados contra la langosta antes de 1924, "Reglamento de la ley federal de plagas”, en La plaga de langosta en México, p. 163.

59 En el artículo 17 se lee: "corresponde exclusivamente a la Junta [...] declarar cuáles son las zonas invadidas, cuáles las zonas amenazadas y [...] de haber desaparecido la plaga total o parcial". "Reglamento de la ley federal de plagas", en La plaga de langosta en México, p. 163.

60 Castonguay, "Creating an Agricultural".
} 
europeos que desde finales del siglo xix habían discutido en torno a la reglamentación cuarentenaria, y cuya experiencia científica y servicios agronómicos habían sido hasta entonces - desde la época de la plaga de la filoxera de la vid, a fines de la década de 1870-importante inspiración para los científicos mexicanos. ${ }^{61}$

\section{Observar y experimentar para combatir}

La investigación científica fue parte importante de la acción del gobierno federal para erradicar la plaga de langosta. En un comienzo, la defensa agrícola se vinculó más a la investigación en fitoparasitología que a la entomología, y conectó dos diferentes ámbitos de acción del gobierno: la administración agraria y la sanitaria. Así, en las campañas se vincularon las oficinas de agricultura de la Secretaría de Fomento con las oficinas de salubridad: el Departamento de Salubridad e Higiene y el Instituto de Higiene. ${ }^{62}$ Así nació la Comisión Científica Exploradora de la Plaga de la Langosta encabezada por el profesor Carlos C. Hoffmann, jefe de la sección de Parasitología del Instituto de Higiene y catedrático de zoología de la Universidad Nacional. Esta comisión

${ }^{61}$ La presencia de la sanidad vegetal, p. 16. En Estados Unidos las invasiones de chapulín (saltamonte, grasshopper) fueron combatidas por organizaciones de productores, autoridades locales y estatales, y también por el UsDA. Una gran plaga de este insecto entre 1933 y 1934 derivó en mayor regulación del USDA en la defensa, por medio de su Bureau of Entomology and Plant Quarantine, bajo el principio de controlar las invasiones para proteger los cultivos, según Parker, Grasshopper Control, pp. 7-12. Véase Castonguay, "Creating an Agricultural"; BuJ BuJ, "International experimentation"; para Francia, Castonguay, "The transformation”, pp. 267-284; para España, BuJ Buj, "Control de las plagas", pp. 6-14, 17-22, pp. 3-7.

${ }^{62}$ Informe de la Comisión Científica, p. 2. La primera expedición para estudiar la plaga de langosta había sido en 1880, del ingeniero agrónomo José C. Segura, profesor de la Escuela Nacional de Agricultura y Veterinaria de San Jacinto. Estudió este insecto en Chiapas, Tabasco y Oaxaca. Rodríguez Vallejo, Historia de la fitosanidad en México, p. 23. 
se instaló en Veracruz, donde los daños y la contaminación de aguas por langostas muertas (especialmente en Cosamaloapan y Minatitlán) eran una emergencia. ${ }^{63}$

Durante el segundo semestre de 1924 la Comisión trabajó en la recolección de muestras, observó la trayectoria de las mangas de langosta, realizó entrevistas y cuestionarios a las autoridades municipales para conocer el estado biológico de la langosta, sus particularidades morfológicas, patrones de reproducción y desplazamiento, y para establecer un mapeo de las áreas gregarígenas (de ovoposición y cría), tanto como de la localización y desplazamiento de las mangas en Veracruz, principalmente, pero también en zonas aledañas. Se construyeron laboratorios en la Dirección General de Salubridad del Estado de Veracruz, primero, y después en las instalaciones de la Escuela Secundaria y Preparatoria de Córdoba, para el análisis de muestras. ${ }^{64}$ Los estudios de esta Comisión Científica se centraron en el desarrollo de la plaga y de sus movimientos, en los factores que influían en el crecimiento del fenómeno para entender el estado en que se encontraba la plaga y prever su posible curso. Para el grupo de especialistas, atender los puntos anteriores significaba construir "la base científica de un combate racional de la plaga" ${ }^{65}$ Ello respondía plenamente a los debates de esa época; por ejemplo, en la Conferencia Internacional de Fitopatología y Entomología Económica (Wageningen, Países Bajos, 1923) los científicos habían destacado la necesidad de una base biológica en toda campaña de defensa agrícola y control de plagas, lo que

${ }^{63}$ Informe de la Comisión Científica, pp. 3, 116. Los otros miembros eran el doctor Alfonso Dampf, especialista de la sección de Parasitología del Instituto de Higiene, profesor de entomología en la Escuela Nacional de Agricultura de Chapingo y exentomólogo oficial del gobierno de Alemania en las colonias del África Central; Gerardo Valera, pasante de medicina y ayudante de la sección de Parasitología del Instituto de Higiene, y dos estudiantes de medicina ayudantes de campo, Antonio Ramírez Laguna y Leopoldo Ancona.

${ }^{64}$ Informe de la Comisión Científica, p. 7.

${ }^{65}$ Informe de la Comisión Científica, p. 4. 
suponía un desplazamiento desde la fitoparasitología en favor de la entomología. ${ }^{66}$

Los estudios de la Comisión Científica se centraron en analizar los métodos y mecanismos más convenientes para detener el avance de la langosta, a partir de sus investigaciones en la zona del Golfo. Sobre las máquinas construidas para destruir los huevos o los mosquitos saltones, señaló que sus alcances eran limitados. En todo caso, la Comisión Científica consideró que los métodos manuales eran más efectivos: a saber, el arado de las tierras en donde hubiera huevos de langosta y los zanjones y las barreras de láminas para las langostas en estado de saltón. En el caso de las brigadas formadas para matar la plaga, notó que "la organización de corporaciones locales y la cooperación de fuerzas voluntarias y obligadas, por lo general, no alcanzan para dominar la plaga”. En suma, las brigadas de vecinos de los pueblos ofrecían resultados escasos. La Comisión Científica recomendó sobre el uso de venenos tener en consideración "la psicología de los pueblos campesinos" y la realización de pruebas. El uso de lanzallamas se consideró un método costoso, aun cuando la gasolina era donada por las compañías petroleras: “el consumo que puede hacer una cuadrilla de 20 hombres es de 70 litros por día y lo que se lograba incinerar con esta técnica era unos 20 kilos de insecto" ${ }^{67}$

66 Debates bien conocidos por Hoffmann y Dampf gracias a su contacto con parasitólogos europeos y estadounidenses en los congresos internacionales de entomología (1925) y con el responsable de los servicios entomológicos del USDA, Leland Ossian Howard, actor central en el diseño de la legislación contra plagas agrícolas en Estados Unidos, quien había hecho investigación a comienzos de siglo en el norte de México sobre el picudo del algodón. Véase especialmente el ya citado trabajo de CASTONGUAY, "Creating”, y el "Informe del Dr. Alfonso Dampf sobre su participación”, pp. 686-701.

67 Informe de la Comisión Científica, p. 81. El dato es relevante: el estado de Veracruz, centro de las acciones de esta Comisión, además de mantener una economía agrícola próspera y diversa, e importantes industrias y agroindustrias, era también núcleo del auge exportador petrolero, responsable de 
Finalmente, la Comisión se concentró en el análisis de métodos biológicos de control de la plaga, como el uso del Coccobacillus acridiorum, descubierto por el microbiólogo francocanadiense Felix D’Herelle en 1911 en Yucatán, a instancias de la Cámara Agrícola y del gobierno yucatecos. D’Herelle propuso el empleo de una enfermedad microbiana, una enteritis causada por el Coccobacillus acridiorum, para afectar por contagio mortalmente a las langostas y acabar con la plaga. ${ }^{68}$ La comunidad científica de biólogos y parasitólogos recibió con beneplácito el uso del Coccobacillus acridiorum en Europa y también en otros países latinoamericanos. D'Herelle después viajó a Argentina para investigar sobre métodos biológicos de control del acrídido, invitado por el Ministerio de Agricultura de ese país. Pero poco después se vio que el uso del Coccobacillus acridiorum arrojaba resultados contradictorios, tanto en México como en Argentina, así que las campañas con bacterias y hongos patógenos dejaron de utilizarse y no se recomendaron como método para la matanza de la langosta. ${ }^{69}$

Para fines de 1926 la plaga de langosta había perdido su fuerza devoradora y las acciones urgentes para su exterminio cesaron. Fue entonces cuando un repentino e importante brote de fiebre aftosa en los estados de Veracruz y Tabasco, de amenazadoras

transformaciones medioambientales en la región. La reacción de las compañías petroleras privadas y extranjeras a las campañas antiacridias de la década de 1920, es cuestión que también merece mayor atención de los estudiosos.

${ }^{68}$ López Vallejo, Instrucciones para combatir la plaga, pp. 3-4, 11-12.

69 Deveson y Martínez, "Locusts in Southern”, pp. 278-279. En México, Gerardo Varela y Enrique Beltrán, quien fue el primer biólogo titulado en México, concluyeron que el uso de bacterias para eliminar la plaga de langosta no era efectivo. El Coccobacillus acridiorum era un huésped habitual en la Schistocerca paranensis, nombre científico de la langosta, y por lo tanto no causaba epizootia alguna. Beltrán, "Contribución al estudio”, pp. 1-12. Beltrán tendría luego una larguísima carrera como docente, investigador y en puestos públicos. Es conocido como uno de los fundadores de la zoología conservacionista y del estudio de la fauna marina. También se dedicó al estudio de los protozoarios y parásitos causantes de las enfermedades tropicales. 
proporciones, condujo, en poco menos de dos años, a la reestructuración del servicio de defensa agrícola y pecuaria, al establecimiento de legislación cuarentenaria interior y exterior, ${ }^{70} \mathrm{y}$ a los primeros convenios sanitarios internacionales con Estados Unidos, diseñados para el combate de la fiebre aftosa. ${ }^{71}$ El 25 de enero de 1927 el presidente Plutarco Elías Calles disolvió la Junta Nacional Directora de la Campaña contra la Langosta y creó la Oficina para la Defensa Agrícola bajo la dependencia de la Secretaría de Agricultura y Fomento, con competencia exclusiva para el estudio, prevención y combate de las plagas agrícolas y pecuarias. ${ }^{72}$ Con esta oficina, el gobierno federal comenzaba una nueva etapa en el diseño jurídico y legal, institucional y organizacional, para prevenir y controlar los insectos y las enfermedades agrícolas, y disponer de los recursos económicos necesarios para estos fines.

Pese a sus limitados alcances en materia de nuevos métodos para eliminar la plaga del acrídido, la Comisión Científica Exploradora de la Plaga de la Langosta había marcado huella y abierto una nueva etapa en la historia de la entomología mexicana, así como en la historia de la defensa agrícola en el país. Con su accionar e investigaciones, construidas sobre la premisa de que la única forma de erradicar la langosta como plaga era por medio de la investigación científica, dejó atrás la época en que éstas eran concebidas como un asunto político o como un problema exclusivo de la población rural, de los poderes municipales, y de intereses económicos agrarios. ${ }^{73}$ Ciertamente, la investigación

70 Secretaría de Agricultura y Fomento, Estudios sobre las plagas.

71 Al respecto, véase el estudio de Machado, "Aftosa and the MexicanUnited States".

72 Diario Oficial (27 ene. 1927) (28 ene. 1927) y (29 ene. 1927), "Decreto creando el Departamento de Defensa Agrícola” (26 dic. 1926), en CuAdros CAldas, Catecismo agrario, pp. 266-267; La presencia de la sanidad vegetal, p. 16; Navarro de Palencia, Los servicios fitopatológicos en México, p. 17.

73 Informe de la Comisión Científica, p. 49. 
biológica de la langosta se encontraba aún en sus comienzos y el principal obstáculo era el desconocimiento de las causas de su "reproducción en masa", por lo que la Comisión insistía en la necesidad de continuar con los estudios biológicos para obtener los "puntos de ataque" en el diseño de una campaña racional y evitar "falsos caminos y el empleo de métodos inútiles que no solo no darían resultado alguno sino acrecentaría el mal". Pero, gracias a esta campaña y esta Comisión Científica, se formó un acervo de conocimientos teóricos, científicos y técnicos de invaluable relevancia regional e internacional sobre la biología de la langosta centroamericana y los métodos para combatirla. ${ }^{74} \mathrm{El}$ combate al insecto mostraba, tanto a las autoridades como a los agricultores, la fértil contribución de las ciencias a la estabilidad rural y bonanza de la agricultura. Empero, el estudio sistemático, económico y agrológico de los daños de esta plaga devastadora quedaba aún por avanzarse, a excepción de su impacto en la afectación del agua limpia para beber.

El segundo legado de la Comisión Científica fue propiciar el intercambio de conocimientos y la difusión de información científica útil para la comprensión del problema de las plagas de langosta, y para su prevención y solución. Ello quedaba a medio camino entre los instrumentos decimonónicos del fomento estatal, como eran la propaganda agrícola, por un lado, y el desarrollo de los planes de fomento y modernización agrícola posteriores a la crisis del treinta, orientados a la educación rural y el trabajo in situ de educadores, técnicos, científicos y expertos. Por otro se reconocían las prácticas locales y la creación de consensos a nivel local como factores clave para inducir cualquier cambio entre los productores agrícolas y la población rural. ${ }^{75}$

Por último, el tercer y más relevante legado de la Comisión fue situar el problema de la plaga de la langosta en una doble

74 Informe de la Comisión Científica, pp. 49, 82.

75 Al respecto, véase Gutiérrez NúÑEz, “Cambio agrario”. 
dimensión: nacional e internacional, tal como se venía haciendo en los países más experimentados en materia de ciencias agrícolas. ${ }^{76} \mathrm{~A}$ partir de la evaluación de la trayectoria que seguía la peregrinación del insecto, la cual iniciaba en Argentina, pasaba por América del Sur, América Central y México para extenderse hasta la frontera de Estados Unidos, la Comisión Científica justificó la necesidad de un esfuerzo internacional coordinado para la circulación de información, en aras de atacar el problema a escala mundial, mediante el intercambio formalizado de "impresiones", en especial entre los países de Centro y Sudamérica, en cuyos territorios, ya se sabía con exactitud, se iniciaban los movimientos del acrídido. De esta manera, en México se podrían tener noticias anticipadas sobre el avance de las mangas de langostas, y de la divulgación de los trabajos y estudios efectuados, principalmente en Argentina, Bolivia, Chile y Brasil. Con esta opinión, era claro que para la Comisión Científica el problema de la plaga no era exclusivamente mexicano, sino "panamericano". ${ }^{77}$ El Boletín de la Oficina de la Defensa Agricola de la Secretaría de Agricultura y Fomento reflejaba este

${ }_{76}$ Buj Buj, "International Experimentation”. En 1915 el Instituto Internacional de Agricultura, con sede en Roma, fundado en 1905, organizó una conferencia internacional sobre la langosta, que resultó en un Comité Permanente Internacional para Estudios Acridianos, en 1916, antecedente de la consolidación de la acridiología. Sudamérica fue pionera en crear instrumentos y acuerdos internacionales de cooperación transnacional contra la langosta: en 1913, en Montevideo, la Primera Conferencia Sudamericana de Defensa Agrícola produjo un convenio regional para su control y combate; CASTONGUAY, "Creating an Agricultural", pp. 49 y ss.; AHSRE, Embamex Uruguay, III-297-5, "Conferencia sobre la Langosta, noviembre de 1934”.

77 Se proponía discutir la experiencia y el conocimiento en acridiología generado en otros países del mundo: Rusia, América del sur y del Norte, los estados malayos, España e India. Informe de la Comisión Científica, p. 80. Tal como señala PorTer, "Plagas, pesticidas", p. 7, el propio Dampf, mientras investigaba para la Comisión, se había desplazado a Belice desde Yucatán, para seguir el paso de la langosta. 
debate: al fin de esa década, se discutían los alcances de la acción internacional y la cooperación en el control de plagas, a propósito de los congresos internacionales de entomología, especialmente el IV Congreso celebrado en Ithaca, Estados Unidos, en agosto de $1928 .{ }^{78}$ En otras palabras, para los especialistas, la prevención, control y erradicación de la plaga de la langosta era cada vez más un asunto que concernía a los países por donde ésta se desplazaba.

\section{LAS NUEVAS GUERRAS CONTRA EL ACRÍDIDO}

\section{Nuevas organizaciones: de campañas nacionales a suprarregionales}

"Hágase el combate contra la langosta sin distinción de fronteras políticas."79

En el segundo semestre de 1941, en plena guerra mundial, noticias de un nuevo y fuerte azote de langosta en los campos centroamericanos, particularmente en El Salvador, llegaron a México. ${ }^{80}$ La península de Yucatán también mostraba infestaciones, aunque no tan graves. Pero en Centroamérica, tras décadas de expansión de la frontera agrícola comercial -plantaciones plataneras, plantíos de café, algodón y hule, y también ganado-, se había reemplazado la diversidad de la selva tropical por la especialización en unos pocos productos, lo que podría haber

78 Secretaría de Agricultura y Fomento, Boletín mensual. Órgano de la Oficina para la Defensa, II, pp. 688-701. También en Guatemala y Costa Rica, véase O’Brien, “On Perilous Ground”, y Picado, “En busca de la genética”. 79 "Ponencia del Departamento Fitosanitario de la Dirección General de Agricultura”, en Lucha contra la langosta, p. 39.

${ }^{80}$ Se requeriría un estudio pormenorizado de la cambiante geografía de la plaga, de sus desplazamientos, y un análisis de sus condiciones de desarrollo y combate en cada uno de los países centroamericanos. 
agravado el patrón de infestación. ${ }^{81}$ En El Salvador comenzaba a tomar forma la cooperación internacional en programas de fomento y modernización agrícola con el USDA (científicos estadounidenses establecerían sus bases en El Salvador para conducir el programa de estaciones experimentales en Nicaragua y Guatemala). ${ }^{82}$ Pero aun así, inicialmente los hacendados se negaron a colaborar para combatir el insecto. ${ }^{83}$ Las mangas de langosta asolaban no sólo a El Salvador sino también a Guatemala, al punto de que, según los relatos, enormes manchas de langosta llegaron a detener los trenes, ${ }^{84} \mathrm{y}$ las mangas "iban y venían" como algo natural "del curso regular de nuestra vida cotidiana". ${ }^{85}$ Peligraban los plantíos de cereales, de algodón, e incluso los de hule. La frontera entre Guatemala y El Salvador se había convertido en un área crítica de infestación.

Las alarmas se detonaron en el gobierno mexicano, que, a instancias de la Secretaría de Agricultura y Fomento (SAF), emprendió, junto con el gobierno de El Salvador, gestiones para

${ }^{81}$ Según estudios posteriores de la FAO, las zonas deforestadas por quema ahuyentaban a las langostas, reconcentrando estas su ovoposición en otras áreas; después, cuando las lluvias traían retoños en las zonas antes quemadas, la invasión depredadora del manto vegetal era todavía más grave. RoDRíGUEZ Vallejo, Historia de la fitosanidad, p. 28. Según Parker, Grasshopper Control, p. 13, al lado de condicionantes meteorológicos, debía considerarse que la industrialización de la agricultura brindaba veranos con mayor duración y diversidad de cultivos, que significaban también más alimento para estas plagas. 82 Memoria, Relaciones Exteriores y Justicia, San Salvador, 1945, pp. 22-23. Una panorámica de las contribuciones del USDA a la formación de institutos de investigación y escuelas agrícolas en Centroamérica puede verse en CEPAL, Primera Reunión, pp. 6-9, y, sobre todo, PiCado, "En busca de la genética". 83 La Prensa Gráfica (2 dic. 1941). Posteriormente, las organizaciones de plantadores algodoneros salvadoreños colaboraron pecuniariamente y con equipamiento en la campaña. Según O'Brien, en Guatemala, la United Fruit Company (UFCO), aun siendo afectados sus plantíos, no siempre se mostró cooperativa. O’Brien, “On Perilous Ground”, pp. 179-180.

${ }^{84}$ La Prensa Gráfica (19 dic. 1941).

${ }^{85}$ La Prensa Gráfica (13 feb. 1942). 
coordinar una campaña conjunta, con los demás gobiernos centroamericanos, de exterminio de la langosta. ${ }^{86}$ El propósito de estas gestiones era concertar compromisos para el ataque urgente in situ a las zonas gregarígenas de El Salvador y Guatemala, y evitar, a toda costa, la penetración de mangas de insectos en México. Esta disposición mexicana no era nueva. El gobierno de Lázaro Cárdenas, mediante la creación del Instituto Biotécnico (1934-1940, dirigido por Enrique Beltrán), había desarrollado, entre otras, investigaciones sobre plagas y enfermedades tropicales de plantas y animales. ${ }^{87}$ En ese marco, en 1935 se firmó un convenio con Guatemala para combatir la langosta en la frontera común, siguiendo lo establecido por la Séptima Conferencia Panamericana de 1933 y el Convenio Interamericano de Montevideo de $1934 .{ }^{88}$

Para fines de 1940 esta plaga ya era virulenta en México, y en el curso de 1941 se tornó grave. Mientras, a mediados de 1940 se había dictado una nueva ley federal, la Ley de Sanidad Fitopecuaria (septiembre de 1940), que concedía a la SAF competencia en la cría y provisión de organismos para el control biológico de las plagas, y el fomento de la fabricación nacional de agroquími$\cos .{ }^{89}$ La langosta invadía los estados de Yucatán y Campeche, y también Quintana Roo; más tarde pasó a Tabasco, Chiapas, Veracruz, Oaxaca y porciones de Guerrero, Jalisco y Michoacán, y

86 En El Salvador, en mayo de 1941, una iniciativa particular del doctor Leandro Echeverría, se presentó al Congreso solicitando un plan de acción conjunta El Salvador-México contra la langosta. México, AHSRE, III-440-2, "Legación de México en El Salvador”, ministro Vicente Veloz González a Secretaría de Relaciones, 22 de mayo de 1941.

87 Olea Franco, “One century”, pp. 483 y ss, 492-500.

88 Convenio comentado ampliamente por el embajador en Montevideo, el exgobernador de Colima y revolucionario Basilio Vadillo, quien tenía experiencia en plagas de langosta en ese estado. AHSRE, Embamex Uruguay, Basilio Vadillo, embajador, al secretario de Relaciones, Montevideo, 12 de noviembre y 15 de diciembre de 1934, "Conferencia sobre la langosta”.

89 Rodríguez Vallejo, Historia de la fitosanidad, p. 142. 
hasta Colima. Para fines de 1941, la superficie afectada abarcaba 10 estados, siendo el de Yucatán el de mayor superficie infestada, con 718000 ha, seguido por Chiapas, Tabasco y Veracruz. La Oficina de Defensa Agrícola, de la Secretaría de Agricultura y Fomento, se ocupó de dirigir la campaña de combate a la langosta por medio de sus oficinas de defensa fitosanitaria regional. Llegaron a destruirse más de 22000 t de insectos en un solo año, "en diversos estados biológicos, y se gastó casi un millón de pesos" ${ }^{90}$ Según otra fuente, en el primer semestre de $1941 \mathrm{Yu}-$ catán destruyó 500 t de langosta. ${ }^{11}$ Para septiembre de 1942, una reinfestación procedente de Centroamérica volvió a complicar el panorama de la Defensa Fitosanitaria, como pasó a llamarse desde comienzos de ese año, y sus delegaciones fitosanitarias. El estado más afectado fue Chiapas, que resentía primero las invasiones procedentes de Guatemala, y luego era el último en lograr su eliminación. El estado donde más difícil era el trabajo de las brigadas era Guerrero, muy infestado, pero en zonas "deshabitadas e incomunicadas de esa entidad". ${ }^{92}$

La campaña de entre 1941 y 1942 fue costeada por el aporte conjunto de los gobiernos estatales y la SAF. Según fuentes oficiales, el gobierno del estado de Yucatán, el territorio más infestado, donde las siembras de maíz habían sido arrasadas, se destacó por disponer rápidamente brigadas y colaborar con la delegación fitosanitaria regional bajo la guía del ingeniero Brondo Witte-quien también trabajó en Tabasco-y por ofrecer claros incentivos a la población rural para combatir al insecto. ${ }^{93}$

90 Coronado Padilla, Cortés y Aburto Valencia, Lucha contra la langosta, pp. 9-12.

91 Secretaría de Agricultura y Fomento, Informe (1942-1943), México, 1943 , p. 169.

92 Secretaría de Agricultura y Fomento, Informe (1942-1943), México, 1943 , p. 168.

93 Secretaría de Agricultura y Fomento, Informe (1944-1945), México, 1945, p. 333. 
El gobierno estatal había ofrecido la compra de insectos o huevos por 1.50 centavos el kilogramo de langosta y huevos muertos; resultaron 5 millones de kilogramos de material recolectado por los pobladores de Yucatán. Además, el gobernador del estado, Humberto Canto Echeverría, fijó una contribución extraordinaria adicional de $4 \%$ sobre todos los ingresos ordinarios, más cuotas extraordinarias a los henequeneros, destinadas al Comité Regional Fitosanitario en Mérida. La regularidad de los brotes de langosta en la península yucateca permitía continuidad en las investigaciones en la biología, morfología, taxonomía, hábitos del acrídido y condiciones medioambientales de su reproducción, posibilitando la acumulación de un acervo de conocimientos generado in situ. Así, entre 1941 y 1942 estudiosos en entomología y parasitología de Chapingo experimentaron nuevamente con métodos biológicos de control de la langosta, con regulares resultados, preocupados por explicar la causa del éxito en el combate a la langosta en Yucatán, mas no en su vecino Campeche. ${ }^{94}$

En ese momento crítico, el interés mexicano por acordar con las naciones centroamericanas una estrategia común fue expresado en la ponencia de la delegación mexicana en la Segunda Conferencia Interamericana de Agricultura, realizada en México en julio de 1942. Los científicos delegados por México, del Departamento Fitosanitario de la Dirección General de Agricultura, presentaron una ponencia: "Lucha contra la langosta en los países de América". Allí, en una clara maniobra de diplomacia agraria, se proponía que México encabezara la lucha en la región mesoamericana, con base en los siguientes acuerdos: que se declarase la plaga de langosta como un problema continental; que se designara un comité internacional permanente en la ciudad de México, encargado de reunir información científica, experimental y todo lo relacionado con la plaga; que se estableciera

94 Zurita VelázQuez, Langosta en Yucatán, pp. 32 y ss. 
un instituto especializado en estudiar la plaga en la región americana; y además, que los gobiernos pudieran establecer fábricas de Efussan, el insecticida experimental contra el acrídido (muy utilizado en Argentina), de forma de reducir los costos de su combate. ${ }^{95}$ De la Conferencia, donde se dieron intercambios con expertos en invasiones de langosta en Sudamérica y en Estados Unidos, resultó la creación del Instituto Interamericano de Cooperación para la Agricultura (IICA), financiado por la Unión Panamericana y con sede en Costa Rica, el país centroamericano que contaba quizá con la mayor tradición en cuanto a un cuerpo de expertos especializados en ciencias agronómicas, ${ }^{96}$ e indirectamente, los arreglos mexicano-centroamericanos que vendrían después.

La langosta se convertía en un actor más en el complejo escenario geopolítico continental de $1942 .{ }^{97}$ La infestación y reinfestación se perfilaba -en el panorama de racionamiento de bienes a escala continental, dificultades del comercio exterior y carestía- como una grave amenaza desestabilizante para los gobiernos de la región, inmersos, por otra parte, en las disyuntivas que conllevaba el alineamiento con los aliados y el desarrollo de planes de cooperación económica, agrícola, científica y técnica con Estados Unidos en medio de tensiones sociales agrarias.

95 Coronado Padilla, Cortes Gómez y Aburto Valencia, Lucha contra la langosta, p. 39. Desde mediados de 1941 se dificultó el aprovisionamiento de combustible e insecticidas para combatir la langosta en todo el continente, debido al racionamiento hemisférico del Petroleum Administration for War (PAW). Ello significó un obstáculo adicional para la campaña antiacridia en toda América.

${ }^{96}$ En Costa Rica fundó una Escuela Interamericana de Agricultura (en Turrialba), institución incorporada a la Organización de los Estados Americanos, en 1948. Inter American Institute for Cooperation in Agriculture, Brief History, pp. 2-4. Véase Picado, "En busca de una genética”. Véase PicADo, "En busca de una genética".

97 Resultan en este sentido esclarecedores los estudios de Picado, "En busca de una genética", pp. 108-111, y Russell III, "Speaking of Annihilation", pp. 1505-1510, 1520 y ss. 
En ese contexto, el gobierno británico se contactó por medio del gobernador de Honduras Británica en diciembre de 1941, y después, por medio de su embajada en la ciudad de México en 1942, con las secretarías de Agricultura y de Relaciones Exteriores. El Reino Unido, argumentando la gravedad del brote de langostas que se desplazaba en el Petén, y la gran experiencia de su Imperial Bureau of Entomology en la experimentación taxonómica, biológica y de control de la plaga en varias áreas del globo (África, Medio Oriente, Egipto, sus dominios en India, Australia y Oceanía), ${ }^{98}$ ofrecía a México apoyo científico y técnico de sus expertos entomólogos y acridiólogos contra la langosta, quienes podrían desplazarse por el sureste del país para realizar sus investigaciones. ${ }^{99}$

Pese a que en Londres se concentraba la mayor investigación de largo alcance y a escala global sobre las langostas, la langosta del desierto y otras especies de langosta migratoria, los esfuerzos británicos para conectar con las instituciones mexicanas, reiterados, fueron infructuosos. Marte R. Gómez respondió tardíamente: si Guatemala no aceptaba la cooperación con Gran Bretaña, México podía formar una comisión de entomólogos que colaborara con los expertos. ${ }^{100}$ Empero, los planes no prosperaron, posiblemente por razones geopolíticas: suspicacias

98 Devenson y Martínez, "Locusts in Southern”, pp. 280-282; Buj Buj, "International Experimentation".

99 Simultáneamente se desarrollaban campañas antiacridias en África, Australia, Argentina y Egipto. Esta simultaneidad impactó en la producción científica sobre el acrídido: si entre 1910-1929 la producción científica mundial sobre esta plaga se calcula que llegó a unos 1197 obras y folletos, entre 1930 y 1949 alcanzó 3172 trabajos, calculado a partir de Buj BuJ, "International Experimentation", figura 1.

100 AHSRE, III-245-3, "Relativo a la cooperación de México en el combate contra la langosta en el territorio de Belice", correspondencia entre noviembre de 1941 y junio de 1943, Legación de Gran Bretaña a la Secretaría de Relaciones Exteriores y al secretario de Agricultura y Fomento, ingeniero Marte R. Gómez. 
guatemaltecas debido a la histórica disputa por el Soconusco y el Petén, y por el progresivo peso de la entomología estadounidense en el ambiente científico e institucional agronómico mexicano, que la alejaba de la entomología británica. La estrategia geopolítica en materia agraria de los gobiernos mexicanos se perfilaba cada vez con mayor claridad, despuntando con velocidad al calor del acontecer mundial. La lenta y desinteresada reacción del gobierno mexicano a las insistentes solicitudes del gobierno británico para operar conjuntamente contra la amenaza del acrídido resultaban, por un lado, de la relación de vecindad mexicano-estadounidense, y por otro, de los acuerdos de cooperación en curso con el gobierno estadounidense y otras organizaciones de ese país. Con la Fundación Rockefeller se colaboraba en un amplio espectro de materias científicas: en salubridad, biología, ciencias agronómicas y químicas, genética y extensionismo rural, entre otras, que apoyaban al control fitosanitario. Después, la Comisión Agrícola Mexicano-Americana había fijado la acción colaborativa con el USDA para el combate a las plagas. ${ }^{101}$

Sin embargo, la langosta parecía resistir todo plan de acción conjunto. En 1946, la prensa difundió la imagen de enormes manchas de langosta diseminadas por El Salvador, Honduras y Nicaragua, dañando los sembradíos de maíz. Las mangas devoraban incluso los platanares, algodonales y cultivos de piña, además de las milpas y campos de frijol. Por si fuera poco, en octubre de ese año México se enfrentó a un brote de fiebre aftosa en el Golfo de México, en Veracruz, que comprometía tanto a la población rural como al sustento alimentario en proteínas de las ciudades. El brote de la temida epizootia se sumaba a un desastre previo en una de las zonas de recurrencia de la plaga de

101 Secretaría de Agricultura y Fomento, Informe (1944-1945), México, 1945, pp. 36, 334-335. Véase Gutiérrez, “Cambio Agrario”. Aún resta precisar puntualmente las formas en las que plasmó esta cooperación entre el USDA y las dependencias mexicanas en el combate a la amenaza de la langosta. 
langosta, el desborde del río Papaloapan (1944). ${ }^{102}$ La campaña de erradicación de la fiebre aftosa (foot-and-mouth-disease) generó conflictos sociales; un ejemplo fue el Bajío mexicano, donde se rechazó y resistió al rifle sanitario. ${ }^{103}$ Mientras avanzaba la campaña contra la aftosa, en tierras tropicales de Puebla y Veracruz, lo mismo en Chiapas, despuntaba una nueva colonización, alentada por las nuevas oportunidades que brindaban la agricultura y ganadería comerciales y el acceso a terrenos inafectables para ejidos abierto por la nueva Comisión Nacional de Colonización (enero 1947) ${ }^{104}$ Finalmente, para agravar el panorama, a mediados de 1947 se declaró la emergencia sanitaria por la plaga de langosta.

Pero en esta coyuntura, en la que México tuvo que conjugar dos campañas de defensa, una agrícola y otra pecuaria, las prioridades ya no fueron el control de la plaga, sino su total eliminación y erradicación. En la frontera centroamericana se estableció una barrera sanitaria, una preventiva y defensiva, contra la aftosa, y otra ofensiva, contra el acrídido centroamericano. Así, el centro de operaciones de la campaña antilangosta no se localizó ni en Veracruz ni en Yucatán. Fue en Chiapas, en la ciudad de Tapachula, punto neurálgico en la frontera con Guatemala, donde la oficina de la Delegación de la Defensa Agrícola se constituyó en la punta de lanza de la inmersión de los expertos mexicanos en las realidades de la langosta centroamericana.

Armado con nuevos objetivos, el gobierno federal estructuró la campaña involucrando a nuevos actores e instrumentos

${ }_{102}$ Como consecuencia de éste, se creó la Comisión Técnica para el Estudio de la Cuenca Total del Río Papaloapan.

${ }^{103}$ En diciembre de 1946 se formó una Comisión Mexicano-Americana para la Erradicación de la Fiebre Aftosa. México también encabezó, brindando asesoría técnica, la Campaña Preventiva contra la Fiebre Aftosa en Centroamérica, AHSRE, III-1991-II, Embamex Guatemala, 1947, véanse las páginas que siguen. Sobre la campaña antiaftosa véase el clásico estudio de MACHADO, Aftosa.

104 Aвоiтes, "La Comisión Nacional de Colonización”. 
de combate. En primer lugar, convocó, como era previsto en la reglamentación sanitaria, a las delegaciones fitosanitarias de Veracruz, Campeche, Tabasco, Chiapas y Oaxaca, que recibían además información facilitada por el Bureau of Entomology and Plant Quarantine (USDA). Junto con el personal afectado en las brigadas sanitarias estatales, se destacó a la 31 Zona Militar para el apoyo en la campaña, así como a las gerencias de distritos de riego, por ejemplo, en Chiapas, las oficinas de los distritos de riego en Huixtla y Suchiate. Ferrocarriles Nacionales debía encargarse del transporte de los medios mecánicos e insumos químicos para el combate a la langosta. Los productores yucatecos y tabasqueños contribuyeron, según las fuentes, aportando jornales de trabajo. ${ }^{105} \mathrm{Al}$ final, la campaña implicó una gran movilización operativa de recursos, en una lógica casi militar, al menos en un principio. Lo imperativo era atacar la emergencia.

\section{El nacimiento del CICLA}

Los veranos de 1947 y 1948 fueron especialmente afectados por plagas y epizootias. Fueron necesarias varias partidas extraordinarias adicionales del presupuesto federal a la Secretaría de Agricultura y Ganadería (SAG) para la campaña antilangosta, al ingresar mangas procedentes desde Nicaragua (y agravarse la epizootia del ganado). ${ }^{106}$ Los brotes de langosta se diseminaban por varias entidades del país. ${ }^{107}$ Dado que las zonas selváticas del Petén, Tabasco y Campeche eran inexpugnables para las brigadas por tierra, surgieron nuevas necesidades en cuanto a estrategias de combate y medios técnicos y mecánicos para ello. El personal técnico de la defensa agrícola se multiplicó cinco veces

105 Secretaría de Agricultura y Ganadería, Informe (1946-1947), México, 1947, pp. 42-43.

${ }^{106}$ La SAG se creó en diciembre de 1946 para sustituir a la anterior Secretaría de Agricultura y Fomento, por el presidente Miguel Alemán.

107 El Nacional (12 jul. 1947), p. 1. 
comparado con el año 1940, y el personal de campo se incrementó casi $50 \%$ (de 170 a 250 miembros). ${ }^{108}$ Mientras tanto, en Centroamérica los daños eran severos: las graves infestaciones se convertían pronto en reinfestaciones, incluso las pasturas eran arrasadas. En Guatemala, entre mayo de 1947 y septiembre de ese año la infestación con mangas de acrídidos pasó de 4000 a 10000 km, mientras en El Salvador subió a 4000 km, estaban plagados de langostas, y en Nicaragua desde comienzos de ese año toda la costa del Pacífico estaba tomada por las mangas, y los terrenos, infestados de huevecillos. Algo similar se informaba respecto a Honduras. ${ }^{109}$ Además, los vecinos centroamericanos se hallaban inmersos en profundos cambios agrarios, que posiblemente afectaron de diversas formas a la campaña contra el insecto temerario. En Nicaragua y El Salvador, dichos cambios eran impulsados por la asistencia estadounidense, en tanto que en Guatemala se cimentaba una reforma agraria y una movilización agrarista impulsada por el gobierno del presidente Juan José Arévalo (marzo de 1945-marzo de 1951); después, encontraría su cenit con las medidas del presidente Jacobo Árbenz (marzo de 1951-junio 27 de 1954).

La SAG fijó un cordón sanitario en la frontera chiapaneca, desde donde comandaba la campaña antilangosta en Guatemala, aportando los medios mecánicos y químicos (lanzallamas, equipos de radio, furgones de ferrocarril cuyo uso donó exentos de pago, otorgando franquicias, insecticidas, insumos varios y combustible) y las brigadas de expertos y equipos técnicos de combate, que con simples comunicaciones obtenían libre paso para penetrar en las selvas del Petén. ${ }^{110}$ Frente a la

108 Secretaría de Agricultura y Ganadería, Informe (1954-1955), México, 1955, p. 156.

109 Ministerio de Agricultura San José de Costa Rica, “El combate”, pp. 2-4.

110 AHSRE, Embamex Guatemala, III-991-11, 1947, correspondencia recibida y despachada en ese año. 
gravedad de la situación, el gobierno mexicano tomó la iniciativa regional, aprovechando la aproximación diplomática con los gobiernos democráticos guatemaltecos y un contexto dinámico en el comercio con los países centroamericanos. ${ }^{111}$ En el mes de febrero de 1947 propuso la creación de un Instituto de Sanidad Vegetal y Animal de Centroamérica y México como entidad intergubernamental autónoma, que declaró plagas internacionales a la langosta migratoria y la fiebre aftosa, y zona biológica para el control de plagas el área comprendida "desde el sureste de la República mexicana hasta el límite sur de la República de Costa Rica”. ${ }^{112}$

Después, a diferencia de anteriores campañas de control de plagas, circunscritas al territorio nacional, el gobierno convocó a otra reunión de ministros de Agricultura de las naciones centroamericanas en Tapachula, que tuvo lugar la primera semana de junio de $1947 .{ }^{113}$ La convocatoria a la reunión de ministros evidencia que la SAG y sus expertos buscaban desarrollar en Centroamérica un campo de acción relativamente autónomo, ya no la defensa agrícola sino la sanidad, lo que implicaba un fuerte liderazgo político, científico y diplomático (como lo intentaba también la Comisión Nacional de Irrigación). Ponía de manifiesto, además, la institucionalización de un campo específico de negociación intergubernamental en el área mesoamericana, la defensa por la sanidad animal y vegetal, que exigía no sólo la concertación organizativa y financiera sino también la negociación entre expertos procedentes de distintas escuelas de conocimiento entomológico y agronómico y diferentes concepciones

111 Castillo, Toussaint y Vázquez Olivera, Centroamérica, pp. 131-171. 112 Esta reunión se celebró en San Salvador en febrero de 1947. Memoria de los actos (El Salvador), 1948. Según Giovanni Peraldo Huertas, la zona coincidía con el antiguo territorio de la Capitanía General de Guatemala.

113 El Heraldo (5 jun. 1927). Junta de Ministros de Agricultura en la Ciudad de Tapachula. Tratarán el importante problema creado por el acrídido y buscarán la forma más eficaz para su exterminio total. 
sobre los métodos a seguir para enfrentar a la langosta. La coincidencia con la campaña antiaftosa, el peligro de la escasez de alimentos en pleno periodo posbélico, y un lustro de dinamismo comercial entre México y la región, ${ }^{114}$ pudo facilitar la coordinación de esfuerzos con los gobiernos centroamericanos.

La nueva estrategia se plasmó en dos innovaciones institucionales, en México y para la región centroamericana. Por un lado, una oficina, la Dirección General de la Defensa Agrícola, creada entre mediados de 1948 y comienzos de 1949. Junto con ella, el Comité Internacional para el Combate de la Langosta en Centro América y México (CiCla), fundado el 21 de junio de 1949. Se trataba de un nuevo organismo intergubernamental, conformado por delegados de cada país, los ministros de agricultura y expertos en control de plagas de El Salvador, Guatemala, Honduras, Nicaragua, Costa Rica y México, con la participación de un comisionado por la Organización de las Naciones Unidas para la Alimentación y la Agricultura (Food and Agriculture Organization of the United Nations, FAO). ${ }^{115}$ Cada delegación nacional tenía derecho a un voto; en caso de empate, desempataría el voto del comisionado por la FAO, y cada una aportaría por igual a financiar un fondo común. Presidido primero por el ingeniero Darío L. Arrieta Mateos, responsable de la Dirección General de Defensa Agrícola de México, luego por el ingeniero costarricense Francisco Seravalli, el ciclo de vida de la organización fue de casi una década. Las sedes fueron rotativas, primero en Managua, ${ }^{116}$ después en San Salvador, su

${ }_{114}$ AHSRE, Embamex Guatemala, III-12-51-12, Informes políticos (enero de 1952).

115 Los estudios sobre este comité son escasos y la mayor parte recientes; hace falta profundizar en los intereses de cada uno de los países miembros y las dinámicas locales, sus particularidades, y las distintas experiencias de coordinación operativa y científica. Al respecto, Peraldo Huertas, Plagas de langosta, pp. 259-286.

116 Además de presidir el CICLA, y de trasladarse por toda Centroamérica y hasta Panamá en trabajos de campo y coordinación, el ingeniero Darío Arrieta 
localización provocó resquemores entre los gobiernos, sobre todo en el momento crítico de la reunión ordinaria del cicla en Managua, poco después del golpe y derrocamiento del gobierno de Jacobo Árbenz en Guatemala. ${ }^{117}$ El convenio original se refrendó con modificaciones, en julio de 1951. ${ }^{118}$

El cicla implicó una revolución organizativa y tecnocientífica en la historia de la defensa fitosanitaria en México y América Central. ${ }^{119}$ Por principio de cuentas, fijó la definición de un problema común, la emergencia sanitaria por la invasión de langosta en el área mesoamericana. Además, estableció un criterio estrictamente biológico -no político ni territorial- para el combate y vigilancia defensiva contra la langosta centroamericana, un aspecto que sería vertebral desde entonces en las campañas contra la plaga de langosta. Como puede verse en el mapa 2, la delimitación de esta zona biológica era la resultante de varias décadas de estudio en las ciencias naturales, las invasiones de langostas migratorias en el área, invasiones que se desplazaban por el Golfo y el Istmo.

El cicla, además, formalizó la asociación de dos ámbitos de acción en esa campaña transnacional: el burocrático

fungía como "agregado agrónomo" en la embajada mexicana en Managua. AHSRE, III-1661-16, embajador Alfonso de Rosenzweig Díaz a Secretaría de Relaciones, 15 de noviembre de 1950.

117 AHSRE, XII-565-14, Telegrama cifrado, Embamex Nicaragua a Luis Padilla Nervo (secretario de Relaciones) (2 de julio de 1954).

118 Diario Oficial, El Salvador (3 sep. 1951), t. 152: 162. Las reuniones de ministros prosiguieron, como parte del mecanismo de funcionamiento del nuevo organismo; fueron decisivas las de 1949 y 1951, que crearon nuevas estrategias de combate colaborativo plasmando dos convenios de coordinación internacional de combate de la langosta (21 de junio de 1949 y 14 de julio de 1951, véase Memoria de los actos (1950-1951)).

119 Respondía, como había señalado el máximo experto en langostas en 1943, B. P. Uvarov, a la "new anti locust policy", fundada en el principio de que el combate contra la langosta debía hacerse como esfuerzo internacional en las zonas gregarígenas, y debía ser permanente, para prevenir la formación periódica de núcleos de infestación. Uvarov, “The Locust”, pp. 114-116. 


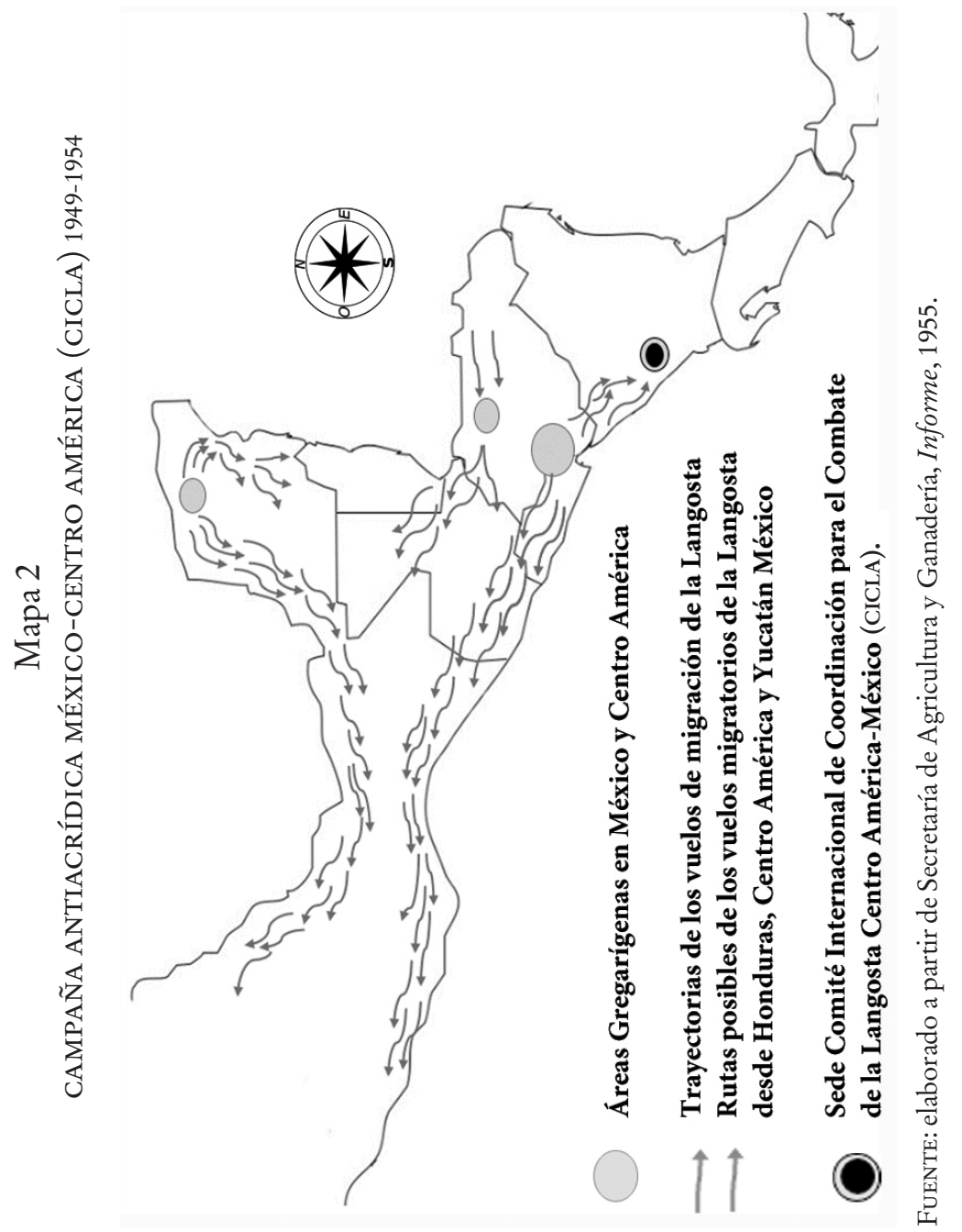


administrativo y el científico-técnico. La gestión operativa y la coordinación administrativa, material y financiera de la campaña cooperativa contra la langosta centroamericana eran aspectos decisivos para su buen resultado: cada país debía aportar fondos en dos pagos anuales, en principio 15000 dólares, y las cuotas extraordinarias que se necesitaran. De la aportación total, $30 \%$ se destinaría a investigación científica, 30\% a administración, y 40\% al gasto en insumos materiales: vehículos, aeroplanos, insecticidas y maquinaria. Debían instalarse laboratorios, desarrollarse trabajo de campo, elaborarse una cartografía de la diseminación del insecto, y coordinarse el movimiento de las brigadas internacionales y de los equipos. Las franquicias aduanales y el libre tránsito de los recursos humanos y técnicos sería compromiso obligado de todos los gobiernos participantes, y los gastos de personal y las brigadas técnicas internacionales serían costeados independientemente por cada país, a excepción de los equipos de expertos de la FAO que serían pagados por el CiClA.

Las labores técnicas, sin embargo, quedaban a cargo del recién fundado organismo transnacional y su cuadro de expertos acridiólogos, la FAO. ${ }^{120}$ Este organismo de las Naciones Unidas se había abocado, entre sus múltiples funciones, a desarrollar investigaciones y campañas contra la langosta del desierto en el Mediterráneo, África y Asia. ${ }^{121}$ La autonomía científico-técnica de los cuadros de expertos de la FAO y toda la nueva arquitectura burocrática suprarregional para el control y erradicación de la langosta no implicaba, sin embargo, la pérdida de competencia de los poderes locales ni de las autoridades nacionales, o

120 Artículo 10: “El Comité prestará toda la colaboración con FAO según el contrato establecido con este organismo para el éxito de los trabajos, con la debida autonomía para la conducción de su labor en la forma y condiciones que las necesidades técnicas lo ameriten”, Diario Oficial, El Salvador (3 sep. 1951), t. 152: 162, p. 5302.

121 AHSRE, XII-423-13, “Comité Nacional de enlace del gobierno de México con la FAO. Langosta del desierto, Comités Técnicos asesores”. 
la puesta en entredicho de la soberanía de cada país en aras de un intervencionismo sanitario supranacional. En virtud de ello, por ejemplo, el gobierno mexicano comenzó a distinguir en sus informes sobre la campaña antiacrídido "los materiales destinados a la Campaña en México" y los destinados a "la Campaña en Centroamérica". ${ }^{122}$ Pero fue un hecho la jerarquización entre los expertos que formaban los grupos de trabajo en las reuniones cuatrimestrales del cicla, y en el trabajo de campo. Asimismo, el resultado fue la multiplicación de los niveles de coordinación administrativa, técnica y científica entre las diferentes agencias de cada gobierno (agricultura, sanidad, transportes y comunicaciones, hacienda), los distintos intereses y prioridades de cada país y, sobre todo ello, la coordinación científica.

Los encuentros y desencuentros científicos entre los cuadros de expertos centroamericanos y mexicanos, muchos de ellos entrenados en universidades estadounidenses y por los entomólogos del USDA, y las prioridades y estrategias de los expertos de las Naciones Unidas, la FAO, debieron de ser frecuentes. En 1952 los países centroamericanos, después de renovar en San Salvador la continuidad de la campaña conjunta con México contra la langosta, suscribieron, en el marco de la FAO, la Convención Internacional de Protección Fitosanitaria (CIPF) de diciembre de 1951, un acuerdo mundial de sanidad vegetal, dirigido a proteger las plantas cultivadas y silvestres mediante la prevención de plagas, al que México se adhirió recién en 1975. ${ }^{123}$

122 Secretaría de Agricultura y Ganadería, Informe (1954-1955), México, 1955, Cuadro "Materiales”, s/n; Ahsre, XII-565-14, "Resumen general de las labores de la campaña (marzo-junio de 1954)”.

123 Asamblea Nacional de la República de Nicaragua, "Convenio para la continuación”. México y los países centroamericanos constituyeron el Comité Internacional Regional de Sanidad Agropecuaria (CIRSA), en San Salvador, el 29 de octubre de 1953. Peraldo Huertas, Plagas de langosta, p. 247. Las razones por las que México suscribió tardíamente este convenio mundial de 1951 deberán explorarse detenidamente en el futuro. 
Mientras tanto, las tensiones sociales, políticas y geopolíticas atravesaban toda la región, y es bien conocido el desenlace abrupto, la intervención que derrocó al presidente Jacobo Árbenz en el verano de 1954. Las fuentes sugieren que, en medio de ello, la langosta era vista no sólo como el epítome de una amenaza y un peligro de la naturaleza, sino, además, como un inagotable laboratorio entomológico y políticoinstitucional a escala transnacional.

Como botón de muestra, en las reuniones de los periodos $\mathrm{V}$ a VII del CICLA (julio de 1953 a julio de 1954), los representantes mexicanos tomaron la iniciativa, exponiendo prioridades estratégicas muy claras: debía formarse una nueva brigada de control en la frontera mexicanoguatemalteca, e intensificarse la ayuda técnica y material a Honduras, El Salvador, Nicaragua y Guatemala. Junto con ello, los representantes de México solicitaron que el experto acridiólogo de la FAO, el entomólogo español Eugenio Morales Agacino -quien se había formado en la campaña anti locust en el Sahara durante los años cuarenta y había construido un insectario del cicLA en Managua, y trabajado también en El Salvador- se ocupara de dirigir la creación, un lustro después de iniciada la campaña, de un insectario completo en Mérida, Yucatán. Solicitó también, en una especie de vuelta de tuerca defensiva ante los problemas geopolíticos que la caída del gobierno guatemalteco había detonado en la región, ${ }^{124}$ que el CICLA se ocupara de impartir cursos de formación y entrenamiento en la ciudad de México, a cargo del doctor Eugenio Morales Agacino. ${ }^{125}$ Por último, la solicitud mexicana señalaba, en una clara estrategia de geopolítica científica: considerando el estado del trabajo por el CICLA, es imprescindible

${ }^{124}$ Un estudio profundo e innovador sobre el papel de México en el golpe en Guatemala en LoAEzA, "La fractura”, pp. 761-784.

125 Ello sugiere, además, la recuperación por los científicos y técnicos de la Secretaría de Agricultura y Ganadería de México de las experiencias científicas en el Sahara español. 
"tener contacto con los funcionarios de Belice, juzgando de gran valor para el buen éxito de las labores del cicla se conozca con exactitud la situación de la langosta en ese territorio”. ${ }^{126}$ ¿Había llegado el momento del repliegue en la diplomacia agraria del gobierno mexicano en Centroamérica, o simplemente una momentánea y estratégica toma de distancia del panamericanismo, para voltear hacia el frente interno e internacional?

\section{EPÍLOGO}

ITINERARIOS DE DOS COMBATES:

CIENCIA, GEOPOLÍTICA Y TECNOLOGÍA

Este trabajo es, sobre todo, una invitación a demostrar la potencialidad del estudio histórico del combate a las plagas como avenida para examinar la construcción de instituciones y el know how especializado en la defensa agrícola y sanidad animal y vegetal a lo largo del siglo xx. Se ha buscado explicar, con relación al recurrente combate a las plagas de langosta, el surgimiento de una arquitectura institucional y tecnocientífica especializada en el control de plagas. Las campañas de control de plagas fueron una instancia importante en el proceso de formación de una burocracia especializada en investigación y extensión agropecuaria, y en su vinculación con una red internacional de científicos e instituciones que encontraron en la defensa sanitaria un campo de experimentación global hacia la construcción de una comunidad tecnocientífica, que trabajaría de acuerdo con una misma agenda y similares presupuestos científicos, haciendo frente a problemas semejantes.

Los combates contra la llamada langosta centroamericana instrumentaron muy diversas formas de ataque al insecto, que

126 AHSRE, XII-565-14, "Informe sobre el periodo ordinario del CICLA, (julio de 1954), por vicecónsul Rafael Herrera Celis, Managua, al secretario de Relaciones Exteriores de México". 
fueron variando de acuerdo con la experiencia práctica en el campo, de ensayo y error, y gracias a los avances científicos en el conocimiento del insecto, así como con el cambio tecnológico. En términos generales, puede decirse que la variación fundamental en los métodos de combate tuvo que ver, por un lado, con los métodos y las estrategias, y por otro, con los medios instrumentados. Mientras en la primera fase del combate al acrídido se enfatizó la lucha en el campo, fundamentalmente a través de la destrucción de las huevas y la captura de los insectos, así como mediante instalaciones que intentaban detener su diseminación (zanjas, barreras), en la segunda fase la estrategia se modificó radicalmente y se orientó a la aniquilación total, la destrucción y el exterminio de las mangas. Por lo tanto, si en algún momento se había intentado una lucha contra el acrídido apoyada en la identificación y manejo científico de sus enemigos naturales -un combate conducido por medios mecánicos y biológicos-, en la segunda fase, y especialmente después de 1942, la guerra total contra el insecto concentró el eje de las campañas de defensa y eliminación en los medios químicos.

A comienzos de los años veinte, la Junta Nacional Directora de la Campaña contra la Langosta había desplegado una importante acción divulgativa y educativa, al difundir los métodos y técnicas que se experimentaban en otros países para acabar con el acrídido, mediante publicaciones en diarios oficiales y boletines, y también por medio de instructores que enseñaban a los campesinos el uso de las bombas lanzallamas e insecticidas venenosos. ${ }^{127} \mathrm{La}$ Junta Nacional recomendaba utilizar los métodos y las técnicas de destrucción según el estado en que se encontraba la langosta. Las recomendaciones de la Junta brindan una idea del estado de las técnicas empleadas para el combate

${ }_{127}$ Diario Oficial de Yucatán (5 oct. 1926). Señala Porter, "Plagas, pesticidas", que la mayoría eran derivados de arsénico, de alta toxicidad y contaminantes de tierras, plantas y aguas, pp. 5 y ss. 
contra el insecto. Para destruir las huevas del insecto en los campos, podían utilizarse bueyes y arados (o una tabla pesada con clavos grandes que se arrastraría por el terreno), y animales domésticos. Para exterminar el acrídido apenas nacido se sugería la bomba lanzallamas, que disparaba a distancia un chorro de fuego. En el caso de los mosquitos o saltones, se indicaba el uso de zanjas y barreras (de zinc o con corral). Los insectos subían y quedaban atrapados, cayendo sobre un recipiente de madera o zanja con petróleo o sosa cáustica. Para la langosta voladora, se recomendaba atraparla cuando desovara, o bien al momento de sacudir los árboles donde esta se posara. ${ }^{128} \mathrm{La}$ Comisión también recomendaba el uso de cebos envenenados e insecticidas. Los cebos podían emplearse para atraer a la langosta, debían diseminarse en horarios en que los insectos se alimentaban, preparados con salvado o alfalfa, arsénico, melaza, cítricos y agua. La Junta Nacional seleccionó otras fórmulas sugeridas por el USDA a los granjeros, del entomólogo B. B Fulton, de Oregon, entre otros. ${ }^{129}$ Por entonces, el uso de las sustancias químicas no estaba generalizado en México. Fuese solas o en alguna mezcla con petróleo o derivados, se rociaban usando bombas de aspersión, jeringas de jardinero o simples regaderas de mano; su aplicación podía ser en polvo o en agua. ${ }^{130}$

Las fuentes no permiten reconstruir con exactitud sus formas de aplicación, pero brindan algunos indicios sobre las dificultades surgidas. Por ejemplo, el 4 de octubre de 1924, el presidente de la junta de defensa local del municipio de Medellín, Veracruz, informaba que los campesinos decidieron "llevar a cabo la citada destrucción por medio [de la] recolección" del acrídido, por no dar resultado los lanzallamas. ${ }^{131}$ En Yucatán los

128 Diario Oficial de Yucatán (4, 5, 7, 8 oct. 1926).

129 Diario Oficial de Yucatán (4, 5, 7, 8 oct. y 11 nov. 1926).

130 Diario Oficial de Yucatán (11 nov. 1926).

131 AGN, $P, O-C$, c. 169, exp. 426 P-2. El presidente de la junta de defensa de Medellín a Álvaro Obregón (4 de octubre de 1924). 
habitantes de Tizimín (cabecera municipal) explicaron que los encargados de verificar las tareas de exterminio "apenas si se detienen muy corto tiempo trayendo unos aparatos que resultan deficientes en la práctica". ${ }^{132}$

Las campañas centroamericanas, dos décadas después, adoptaron una estrategia bélica -de aniquilación-contra la langosta, a la par que contribuyeron al establecimiento de una nueva etapa en la investigación entomológica y fitoparasitológica contra este insecto. No contamos con indicios documentales completos acerca de los métodos empleados en los campos infestados, ni en México ni en América Central. ${ }^{133}$ Las fuentes muestran que se establecieron cordones sanitarios en la frontera entre Chiapas y Guatemala (en medio de daños parciales al puente que atravesaba el Suchiate, según los informes diplomáticos) y también en las fronteras que compartían Guatemala, Honduras y El Salvador, y Honduras y Nicaragua. Brigadas internacionales armadas con medios mecánicos y tecnologías de comunicación y transporte propios de campos de batalla penetraron las zonas infestadas -pobladas unas e inhóspitas otras-. Así, al lado de los ferrocarriles, que servían como transporte o como furgones de operaciones, potentes jeeps con turbinas equipados con espolvoreadores (fumigadores), que incluso eran fotografiados como símbolos de la victoria contra el insecto, ingresaban con franquicia desde el sureste mexicano a los países vecinos. Buena parte de estos era contribución de México a la campaña. Junto con ellos, modernos lanzallamas Aeroil dotados con bombas "poderosísimas"

132 AGEY, Congreso del Estado, Comisión de Hacienda, c. 29, vol. 29 exp. 22 (1925).

133 Al respecto, Cuevas y Rodríguez, "Invasiones de langostas", sobre los saberes locales. Dos ejemplos, el reporte de Alexander Bierig de las aplicaciones de métodos en la lucha antiacridia en Departamento Nacional de Agricultura, "La langosta invasora", pp. 10-18, y Centro Nacional de Agricultura San Pedro de Montes de Oca, "Implementos rústicos e insecticidas". 
(Niagara), gasolina y fuel, talco para las mezclas químicas, y nuevas generaciones de insecticidas organoclorados ("langosticidas"), como el Efussan, ${ }^{134}$ y después de 1945, DDT (diclorodifenil-tricloroetano) y diversas mezclas. Al aumentar su empleo en el sureste del país y simultáneamente en Centroamérica, se incrementó la demanda de estos agroquímico, que las modestas fábricas de insecticidas locales no alcanzaban a cubrir. ${ }^{135} \mathrm{El}$ gobierno guatemalteco, por su parte, dependía de las importaciones de insecticidas y pesticidas desde el Suchiate, Nueva Orleans y Los Ángeles; comisionados militares y aeronáuticos estaban afectados a ese tráfico, aunque en ocasiones con renuencia. ${ }^{136}$

Pero en esta nueva etapa, si la langosta era el actor principal, los protagonistas estelares ya no eran los pueblos, ni tampoco los científicos o expertos, sino un revolucionario adelanto de la aviación: los aviones fumigadores. ${ }^{137}$ Señalaba una nota informativa publicada en Tuxtla Gutiérrez en junio de 1947: "El mejor procedimiento para el combate a la plaga es hacerlo por medio de aviones, lo que ha sido probado, exterminándose 41 mangas de langosta de $3 \mathrm{~km}$ de extensión, empleándose aviones tipo Stearman, en la zona fronteriza sur". ${ }^{138}$ La navegación

134 AHSRE, III-991-11, brinda, por medio de una copiosa correspondencia, rica información cualitativa sobre el flujo de estos insumos de México a América Central.

135 Pequeños laboratorios realizaban, in situ y velozmente, el análisis de las mezclas de insecticidas. Secretaría de Agricultura y Ganadería, Informe, México, 1951, pp. 39-41.

136 O’Brien, “On Perilous Ground”, pp. 182-184.

137 La contribución de México con jeeps, aviones fumigadores y gasolina fue significativa. Resta estimarse con precisión, podría haber sido más importante en Nicaragua y Guatemala que en Costa Rica. Secretaría de Agricultura y Ganadería, Informe (1948-1949), México, 1949, pp. 38-41. Por su parte, el aporte de Pemex y Guanos y Fertilizantes (Guanomex) a las campañas centroamericanas (y de la United Fruit Company en América Central) es cuestión que también merece atención de los estudiosos.

138 "Junta de Ministros de Agricultura en ciudad de Tapachula", en El Heraldo (5 jun. 1947). 
aérea para la defensa sanitaria requería de mayor conocimiento meteorológico. Así, en sincronía con estas nuevas necesidades, fue establecida en Mérida, Yucatán, una estación aerológica para todo el sureste, que debía funcionar en colaboración con los observatorios meteorológicos. ${ }^{139}$

Los informes del secretario de Agricultura de México de esos años, entre 1940 y 1955, eran insistentes en resaltar el papel de la aviación en el control de plagas. ${ }^{140}$ Pero, no sólo se trataba de los aviones de los gobiernos de México y Centroamérica al servicio de las campañas antiacrídido, ${ }^{141}$ sino además de los servicios comerciales de la aviación civil de México. Desde la frontera norte entre México y Estados Unidos, pequeñas compañías de aviones dedicadas a la fumigación contra el gusano rosado del algodón se trasladaron ante la creciente demanda de espolvoreos de químicos y DDT al istmo centroamericano, ofreciendo sus servicios para la destrucción del insecto: de una frontera a otra, de un vecino a otros. Para entonces, la langosta migratoria había logrado interconectar las diversas biorregiones a su paso mediante el impulso de medidas locales de control, de la normalización nacional y supranacional de políticas de protección y sanidad vegetal, y de investigación entomológica aplicada, contribuyendo así al nacimiento de una biogeopolítica agropecuaria en México y América Central. En este panorama, resta profundizar en el papel que desempeñó México como difusor de instituciones, tecnologías, saberes científicos y expertos para la formación de los servicios de defensa y sanidad agropecuaria en la región, y como proveedor de insumos químicos para las campañas de destrucción de las plagas en esta configuración geopolítica de la sanidad agropecuaria. Por lo pronto, es claro que, en el periodo de entreguerras, la defensa agrícola quedó

139 Secretaría de Agricultura y Fomento, Informe (1944-1945), pp. 34-35. 140 Sobre la aviación en las campañas africanas, ORGANIZACión DE LAS NACiOnes Unidas Para la Alimentación y la Agricultura, Informe.

141 O’brien, “On Perilous Ground”, pp. 175-194. 
comprendida cada vez más en la sanidad vegetal, primero como principio de política pública nacional, y después como competencia de las Naciones Unidas y sus organismos, y que fue desbordando la sola protección de los cultivos y animales y el control de los riesgos y daños en el campo, para alcanzar y aspirar a la protección de la oferta y calidad de los alimentos y sus consumidores, tanto rurales como urbanos.

\section{SIGLAS Y REFERENCIAS}

AGEY Archivo General del Estado de Yucatán, México.

AGN, P, O-C Archivo General de la Nación, fondo Presidentes ObregónCalles, Ciudad de México, México.

AHSRE Archivo Histórico Diplomático Genaro Estrada, Secretaría de Relaciones Exteriores, fondo Embajada (Embamex) Guatemala, El Salvador y Nicaragua, Legajos Encuadernados, Ciudad de México.

Aboites Aguilar, Luis, "La Comisión Nacional de Colonización y la expansión de la pequeña propiedad rural en México, 1947-1963”, en Historia Mexicana, LXVIII: 3 (271) (ene.-mar. 2018), pp. 1165-1204.

Alberola Romá, Armando (ed.), Riesgo, desastre y miedo en la península Ibérica y México durante la Edad Moderna, Zamora, Michoacán, El Colegio de Michoacán, Alicante, Universidad de Alicante, 2017.

Arrioja Díaz Viruell, Luis A., "Enjambres y nubarrones en el campo oaxaqueño: las plagas de langosta de 1802 y 1853", en Relaciones. Estudios de Historia y Sociedad, xxxIII: 129 (2012), pp. 161-213.

Arrioja Díaz Viruell, Luis A., "Guatemala y Nueva España: historia de una plaga compartida, 1798-1807”, en Revista de Historia Moderna, 33 (2015), pp. 309-323.

Arrioja Díaz Viruell, Luis A., Bajo el crepúsculo de los insectos. Clima, plagas y trastornos sociales en el Reino de Guatemala (1768-1805), Zamora, El Colegio de Michoacán, Universidad de San Carlos de Guatemala, FLAcso Honduras, Universidad Nacional Autónoma de Honduras, 2019.

Asamblea Nacional de la República de Nicaragua, Normas Jurídicas de Nicaragua, "Convenio para la continuación de la campaña contra la langosta, 
Centro América y México, aprobado el 14 de julio de 1951", http://legislacion. asamblea.gob.ni/normaweb.nsf/(\$All)/5F3E6455143E. Consultado el 20 de junio de 2019.

Beltrán, Enrique, Contribución al estudio del Coccobacillus acridiorum D'Herelle, México, Sociedad Científica "Antonio Alzate", Talleres Gráficos de la Nación, 1926.

Brading, David A. (comp.), Caudillos y campesinos en la Revolución Mexicana, México, Fondo de Cultura Económica, 1985.

Buj Buj, Antonio, "Control de las plagas de langosta y modernización agrícola en la España de la segunda mitad del siglo xix", en Geo Crítica, Cuadernos de Geografía Humana, 95 (jul. de 1992), pp. 1-31, http://www.ub.es/geocrit/ geo95.htm. Consultado el 24 de febrero de 2013.

Buj Buj, Antonio, "International Experimentation and Control of the Locust Plague. Africa in the First Half of the 20Th. Century", en Scripta Vetera, Serie Electrónica de Geografía y Ciencias Sociales, 31 (1995), pp. 93-105, http:// www.ub.es/geocrit/locust.htm. Consultado el 24 de febrero de 2013.

Canto SÁenz, Rodolfo, Del henequén a las maquiladoras. La política industrial en Yucatán, 1984-2001, México, Instituto Nacional de Administración Pública, Universidad Autónoma de Yucatán, 2001.

Castillo, M. A., M. Toussaint y M. Vázquez Olivera, Centroamérica, vol. 2, en M. de VEGA (coord.), Historia de las relaciones internacionales de México, 1821-2010, México, Secretaría de Relaciones Exteriores, 2011.

Castonguay, Stéphane, "The Transformation of Agricultural Research in France: The Introduction of the American System”, en Minerva, 43: 3 (ene. 2005), pp. 265-287.

Castonguay, Stéphane, "Creating an Agricultural World Order: Regional Plant Protection Problems and International Phytopathology, 1878-1939”, en Agricultural History, 84: 1 (2010), pp. 46-73.

Centro Nacional de Agricultura San Pedro de Montes de Oca, CosTA RicA, "Implementos rústicos e insecticidas para combatir plagas de insectos masticadores", en Boletin Popular, 60 (abr. 1940). 
Comisión Económica para América Latina (Cepal), Primera reunión del Comité de Cooperación Económica de los Ministerios de Economía del Istmo Centroamericano, Tegucigalpa, 23 de agosto de 1952.

Contreras Servín, Carlos, "Conexión climática del fenómeno de "El Niño" con la plaga de la langosta centroamericana (Schistocerca piceifrons piceifrons, walker) localizada en el estado de Yucatán y la Huasteca potosina", en Entomologia Mexicana, 8 (2009), pp. 347-351.

Coronado Padilla, Ricardo, Luis Cortes Gómez y Horacio Aburto Valencia, Lucha contra la langosta en los países de América, México, Comité permanente de la Conferencia Interamericana de Agricultura, 1944.

Cuadros Caldas, Julio, Catecismo agrario, reedición de la sexta, publicada en 1932, con un estudio introductorio de Guillermo Palacios, México, Registro Agrario Nacional, Archivo General Agrario, Centro de Investigaciones y Estudios Superiores en Antropología Social, 1999.

Cuevas Cardona, Consuelo y María de Jesús Rodríguez López, "Invasiones de langostas y de chapulines en la historia de México (siglos XIx y xx)", en Peraldo Huertas (ed.), 2015, pp. 99-122.

DampF, Alfonso, "Informe del Dr. Alfonso Dampf sobre su participación en el IV Congreso Internacional de Entomología, como representante del Gobierno de México", en Boletín de la Oficina para la Defensa Agrícola, 1928, pp. 686-701.

Departamento Nacional de Agricultura, "La langosta invasora", en Boletin 30, San Pedro Montes Oca, Costa Rica, 1940.

Deveson, Edward y Alejandro Martínez, "Locusts in Southern Settler Societies: Argentine and Australian Experience and Responses, 1880-1940", en Vaz, Joanaz de Melo y Costa Pinto (eds.), 2017, pp. 259-286.

EsCRICHE, Joaquín, Diccionario razonado de legislación civil, penal, comercial $y$ forense con citas del derecho, notas y adiciones por el licenciado Juan Rodriguez de San Miguel, México, Universidad Nacional Autónoma de México, Miguel Ángel Porrúa, Instituto de Estudios Parlamentarios Eduardo Neri, LV Legislatura, H. Congreso del Estado de Guerrero, 1993.

Fernández Prieto, Leida, "Islands of Knowledge: Science and Agriculture in the History of Latin America and the Caribbean", en Isis, 104: 4 (dic. 2013), pp. 788-797. 
Few, Martha, "Killing Locust in Colonial Guatemala", en Few y TORTORICI (eds.), 2013, pp. 62-92.

Few, Martha y Zeb Tortorici (eds.), Centering Animals in Latin American History, Durham, Duke University Press, 2013.

García Martínez, Bernardo y María del Rosario Prieto (comps.), Estudios sobre historia y ambiente en América, II. Norteamérica, Sudamérica y el Pacífico, México, El Colegio de México, Instituto Panamericano de Geografía e Historia, 2002.

García Quintanilla, Alejandra, “Záatal: cuando los milperos perdieron el alma. Una historia de los mayas, Yucatán, 1880-1889”, tesis de doctorado en historia, Chapel Hill, University of North Carolina, 1999.

García Quintanilla, Alejandra, “'Saak” y el retorno del fin del mundo. La plaga de langosta en las profecías del katún 13 Ahau”, en Ancient Mesoamerica, 16 (2005), pp. 327-344.

García Quintanilla, Alejandra, "La langosta, los mayas y el colonialismo en Yucatán, México, 1883", en Relaciones. Estudios de Historia y Sociedad, XXXIII: 129 (2012), pp. 215-249.

GutiérRez NúÑEZ, Netzahualcóyotl Luis, “Cambio agrario y revolución verde: dilemas científicos, políticos y agrarios en la agricultura mexicana del maíz, 1920-1970", tesis de doctorado en historia, México, El Colegio de México, 2017.

Inter American Institute for Cooperation in Agriculture, Brief History of IICA, Costa Rica, Inter American Institute for Cooperation in Agriculture, 2012.

Informe de la Comisión Científica Exploradora de la Plaga de la Langosta en el estado de Veracruz. Presentado al Instituto de Higiene por los comisionados profesor Carlos C. Hoffmann, jefe de la comisión; profesor Alfonso Dampf, miembro de la comisión y Gerardo Varela, ayudante bacteriólogo de la comisión, México, Talleres Gráficos de la Nación, 1925.

Joseph, Gilbert M., "El caciquismo y la Revolución: Carrillo Puerto en Yucatán”, en BRADING (comp.), 1985, pp. 239-276. 
La destrucción de la langosta. Informe rendido por el señor cónsul general de México en la República Argentina, México, Imprenta y Fototipia de la Secretaría de Fomento, 1911.

Lange, Fabian, Alan Olmstead y Paul W. Rhode, "The Impact of Boll Weevil, 1892-1932”, en The Journal of Economic History, 69: 3 (sept. 2009), pp. 685-718.

La plaga de langosta en México, publicado por el Departamento de Información y Propaganda de la Junta Nacional Directora de la Campaña contra la Langosta, Veracruz, México, 1925.

La presencia de la sanidad vegetal en la agricultura mexicana del siglo XX (facsimilar de Fitófilo, edición especial), Servicio Nacional de Sanidad, Inocuidad y Calidad Agroalimentaria, 28 de julio de 2016. http: www.gob.mx/senasica/ documentos/fitofilo-edición. Consultado el 20 de enero de 2019.

León Vegas, Milagros, "La plaga con que castiga Dios los pecados de los hombres: langosta y campo andaluz en la Edad Moderna", en Relaciones. Estudios de Historia y Sociedad, xxxIII: 129 (2012), pp. 87-123.

Lértora Mendoza, Celina Ana (coord.), Geografía e historia natural: hacia una historia comparada. Estudio a través de Argentina, México, Costa Rica y Paraguay, Argentina, Instituto Panamericano de Geografía e Historia, 2009.

LoaEza, Soledad, "La fractura mexicana y el golpe de 1954 en Guatemala", en Historia Mexicana, LXvI: 2 (262) (oct.-dic. 2016), pp. 725-791.

López Vallejo, Eutimio, Instrucciones para combatir la plaga de langostas por medio de cultivos del Coccobacillus acridiorum, México, Departamento de Talleres Gráficos de la Secretaría de Fomento, 1917.

Machado Jr., M., “Aftosa and the Mexican-United States Sanitary Convention of 1928”, en Agricultural History, 39: 4 (oct. 1965), pp. 240-245.

Machado Jr., M., Aftosa. A Historical Survey of Foot-and-Mouth Disease and Inter-American Relations, Albany, State University of New York Press, 1969.

Magaña Ortiz, Cecilia, "Estudio comparativo de la Langosta Centroamericana (Schistocerca piceifrons Walker) en la Huasteca Potosina y el estado de Yucatán”, tesis de maestría en ciencias ambientales, San Luis Potosí, Universidad Autónoma de San Luis Potosí, 2010. 
Martínez Marañón, Ricardo, “Carlos Cristian Hoffman”, en Salud Pública de México (2014), pp. 675-677.

Mas GalvaÑ, Cayetano, "La gestión de la catástrofe. Acción estatal y lucha contra la plaga de la langosta en las diócesis de Murcia y Orihuela (17561758)", en Relaciones. Estudios de historia y sociedad, xxxIII: 129 (2012), pp. 51-86.

МсСоок, Stuart, "Las epidemias liberales: agricultura, ambiente, y globalización en Ecuador (1790-1930)”, en García Martínez y Prieto (comps.), 2002, pp. 223-246.

McСook, Stuart, "Plantas, petróleo y progreso: las ciencias agrícolas y las ideologías de desarrollo en la época de Juan Vicente Gómez, 1908-1935”, en Estudios Interdisciplinarios de América Latina y el Caribe, 14: 1 (ene.-jun. 2003), pp. 67-88.

Memoria de los actos del Poder Ejecutivo en el ramo de Agricultura y Ganadería correspondiente al año comprendido entre el 14 de septiembre de 1950 y el 13 de septiembre de 1951 presentada a la Honorable Asamblea Legislativa por el subsecretario de Agricultura y Ganadería, encargado del Despacho, Don José Nicolás Mora, el 9 de noviembre de 1951, San Salvador, Imprenta Nacional, 1951.

Memoria de los actos de Poder Ejecutivo en los ramos de Relaciones Exteriores y Justicia correspondiente al año de 1947 presentada a la Honorable Asamblea Nacional Legislativa por el Doctor Ernesto A. Núñez, subsecretario encargado del despacho, el 15 de mayo de 1948, San Salvador, Imprenta Nacional, 1948.

Ministerio de Agricultura San José de Costa Rica, "El combate de la Langosta, por el ingeniero Francisco Seravalli C., jefe del Departamento de Defensa Agropecuaria, Boletín Técnico, Ministerio de Agricultura e Industrias", en Boletín Técnico, 8 (1952), pp. 1-11.

Navarro de Palencia, Jesús, Los servicios fitopatológicos en México, Madrid, España, Dirección General de Agricultura, Servicios de publicaciones agrícolas, sin fecha.

O'Brien, Stephen K., "On Perilous Ground: A Social and Environmental History of Escuintla on Guatemala's South Coast, 1928-1962", tesis de doctorado en filosofía, Connecticut, Yale University, 2007. 
OHLEndorf, W., Studies of the Pink bollworm in Mexico", United States Department of Agriculture. Department Bulletin, 1374 (marzo 1926), pp. 1-64.

Olea Franco, Adolfo, "One century of Higher Agricultural Education and Research in Mexico (1850s-1960s), with a preliminary survey on the same subjects in the United States", tesis de doctorado en historia de la ciencia, Massachusetts, Harvard University, 2001.

Olmstead, Alan L. y Paul Rhode, Arresting Contagion. Science, Policy, and Conflicts over Animal Disease Control, Cambridge, Massachusetts, Londres, Harvard University Press, 2015.

Organización de las Naciones Unidas para la Agricultura y la AliMENTACIÓN, Informe del cuadro de expertos de la FAO en la lucha aérea contra la langosta del desierto, Roma, 1959.

Pan-Montojo, Juan, "Las vitiviniculturas europeas: de la primera a la segunda globalización", en Mundo Agrario, revista electrónica, 18 (1er. semestre 2009) https://www.mundoagrario.unlp.edu.ar/article/view/v09n18a08/843 Consultado 9 de octubre de 2009.

Paoli, Francisco y Enrique Montalvo Ortega, El socialismo olvidado de Yucatán: elementos para una reinterpretación de la Revolución Mexicana, México, Siglo Veintiuno Editores, 1980.

Parker, J. R., Grasshopper Control in the American Nations, México, Publicaciones del Comité Permanente de la $2^{\text {a }}$ Conferencia Interamericana de Agricultura, sección 3a, 1944.

Peniche Moreno, Paola, Tiempos aciagos. Las calamidades y el cambio social del siglo XVIII entre los mayas de Yucatán, México, Porrúa, Centro de Investigaciones y Estudios Superiores en Antropología Social, 2010.

Peraldo Huertas, Giovanni (ed.), Plagas de langosta en América Latina. Una perspectiva multidisciplinaria, San José, Costa Rica, Nuevas Perspectivas, 2015.

Picado, Wilson, "En busca de la genética guerrera. Segunda Guerra Mundial, cooperación agrícola y Revolución Verde en la agricultura de Costa Rica”, en Historia Agraria, 56 (abr. 2012), pp. 107-134.

PORTER, Jayson M., "Plagas, pesticidas y ciencias agrícolas entre revoluciones", en Boletin del Fideicomiso Plutarco Elías Calles y Fernando Torreblanca, 89 (sep.-dic. 2018), pp. 1-44. 
Quesada-Román, Adolfo, Flora J. Solano y Giovanni Peraldo, “La plaga de langosta en Costa Rica entre 1859 y 1950”, en LÉRTORA MENDoza, (coord.), 2009, pp. 139-184.

Rodríguez Vallejo, José, Historia de la fitosanidad en México, siglo XX, México, Universidad Autónoma de Chapingo, 2000.

Romero Contreras, Tonatiuh, "Los agrónomos mexicanos y el control de plagas agrícolas a fines del siglo xIX y principios del xx", en Ciencia Ergo Sum, 10: 3 (nov. 2003-feb. 2004), pp. 333-343.

Russel III, Edmund, “'Speaking of Annihilation': Mobilizing for War against Human and Insect Enemies, 1914-1945”, en The Journal of American History, 82 (mar. 1996), pp. 1505-1529.

Savarino Roggero, Franco, Pueblos y nacionalismo, del régimen oligárquico a la sociedad de masas en Yucatán, 1894-1925, México, Instituto Nacional de Estudios Históricos de la Revolución Mexicana, 1997.

Secretaría de Agricultura y Fomento, Boletín mensual. Órgano de la Oficina para la Defensa Agrícola, San Jacinto, D.F., 1928, ts. I y II.

Secretaría de Agricultura y Fomento, Estudios sobre las plagas de las plantas y los animales de México, Tacubaya, México, Oficina para la Defensa Agrícola, 1 de marzo de 1927.

Secretaría de Agricultura y Fomento, Informe de labores de la Secretaría de Agricultura y Fomento, del 1 de septiembre de 1942 al 31 de agosto de 1943, México, Editorial Cvltvra, 1943.

Secretaría de Agricultura y Fomento, Informe de labores de la Secretaría de Agricultura y Fomento, del 1 de septiembre de 1943 al 31 de agosto de 1944, México, Editorial Cvltvra, 1944.

Secretaría de Agricultura y Fomento, Informe de labores de la Secretaría de Agricultura y Fomento, del 1 de septiembre de 1944 al 31 de agosto de 1945, México, Talleres Gráficos de la Nación, 1945.

Secretaría de Agricultura y Fomento, Informe de labores de la Secretaría de Agricultura y Fomento, del 1 de septiembre de 1945 al 31 de agosto de 1946, México, Talleres Gráficos de la Nación, 1946, t. II. 
Secretaría de Agricultura y Ganadería, Informe de labores de la Secretaría de Agricultura y Ganadería, del 1 de septiembre de 1946 al 31 de agosto de 1947, México, Talleres gráficos de la Nación, 1947.

Secretaría de Agricultura y Ganadería, Informe de labores de la Secretaría de Agricultura y Ganadería, del 1 de septiembre de 1948 al 31 de agosto de 1949, México, Talleres gráficos de la Nación, 1949.

Secretaría de Agricultura y Ganadería, Informe de labores de la Secretaría de Agricultura y Ganadería, del 1 de septiembre de 1950 al 31 de agosto de 1951, México, Talleres gráficos de la Nación, 1951.

Secretaría de Agricultura y Ganadería, Informe de labores de la Secretaría de Agricultura y Ganadería, del 1 de septiembre de 1954 al 31 de agosto de 1955, México, Talleres gráficos de la Nación, 1955.

Soluri, John, "People, Plants and Pathogens: The Eco-Social Dynamics of Export Banana Production in Honduras, 1875-1950", en The Hispanic American Historical Review, 80: 3 (ago. 2000), pp. 463-502.

Tranchini, Elina M., "Políticas agrarias y comportamientos sociales: el caso de la plaga de langosta en la región pampeana", tesis de licenciatura en sociología, La Plata, Universidad de La Plata, 1995.

Uvarov, B. P., "The Locust Plague”, en Journal of the Royal Society of Arts, 91: 4631 (22 ene. 1943), pp. 109-118.

Vaz, Estelita, Cristina Joanaz de melo y Lígia M. Costa Pinto, Environmental History in the Making, I. Explaining, Suiza, Springer Nature, 2017.

Zurita VelázQuez, Pedro, “Langosta en Yucatán y Campeche, 1941-1942”, tesis de licenciatura en agronomía, Chapingo, México, Escuela Nacional de Agricultura, 1943. 
